\title{
LA NEGOCIACIÓN IMPOSIBLE (CÁNOVAS Y EL FUERISMO VASCO EN 1876) ${ }^{1}$
}

\author{
por \\ LUIS CASTELLS \\ ARTURO CAJAL \\ Universidad del País Vasco
}

RESUMEN: Tras la restauración de los Borbones en 1875 y la finalización de la guerra carlista, Cánovas del Castillo consideró que era el momento de abordar las especiales relaciones que mantenían las provincias vascas con el Estado. Aquéllas venían disfrutando de una situación por la cual estaban exentas de contribuir al fisco $y$ de prestar el servicio militar, amparando esta peculiar condición en su régimen foral. Cánovas impulsó la Ley de julio de 1876 con el objetivo de modificar ese estado de cosas. Esta Ley suscitó una fuerte reacción en el País Vasco, viviéndose momentos de tensión como consecuencia del rechazo que originó entre ciertos sectores, y que fue encabezado por las instituciones forales. De todas maneras, ante las iniciativas de Cánovas no bubo una posición unánime en el País, delimitándose, a grandes rasgos, dos sectores: uno más partidario de la negociación con el ejecutivo y otro más cerrado a esta posibilidad. El objetivo del artículo es abordar la apasionante coyuntura que transcurrió a lo largo de 1876-1877, y analizar unos hechos que han marcado la bistoria posterior del País Vasco.

Palabras clave: País Vasco. España. Autonomía regional. Fueros. Siglo XIX. Liberalismo.

ABSTRACT: After restoration of Bourbons in 1875 and the ending of the Carlist War, Cánovas del Castillo believed that the time had come to address the special relationship of the Basque provinces with the State. Because of the situation these provinces bad been enjoying, they were free from paying tax and from military service, protecting this particular condition through the "fueros». Cánovas promoted the law of July

\footnotetext{
${ }^{1}$ Considérese este artículo como nuestro pequeño homenaje al 25 aniversario del restablecimiento de las Juntas Generales en el País Vasco.

Este trabajo se ha beneficiado se ha beneficiado de una subvención concedida a grupos consolidados, 9/UPV, 13655/2001.
} 
1876 with the object of changing that state of affairs. This law caused a strong reaction in the Basque Country, which experienced tense moments as the result of the rejection that it met in some sectors of Basque society, led by the foral institutions. In any case, there was no unanimous position in the Basque Country in regard to Cánovas' initiaves, being delimited, broadly speaking, to two factions: one supporting negotiation with the government and other resisting this avenue. The object of this article is to explore the critical phase 1876-1877, and to analyse some facts that have marked later history in the Basque Country.

KEY WORDS: Basque Country. Regional autonomy. Fueros. Nineteenth-century. Liberalism.

La bistoria está siendo revisada o inventada boy más que nunca por personas que no desean conocer el verdadero pasado, sino sólo aquel que se acomoda a sus objetivos. La actual es la gran era de la mitología bistórica. La defensa de la bistoria por sus profesionales es en la actualidad más urgente en la política que nunca. Nos necesitan.

E. Hobsbawm, Años interesantes. Una vida en el siglo XX.

La Ley de julio de 1876 inauguró una nueva etapa en la historia contemporánea del País Vasco al crear una base legal que permitió eliminar el régimen foral tradicional que venían disfrutando las Provincias Vascongadas. Los sucesos que se produjeron en aquellos años fueron vividos por sectores de la sociedad vasca de manera muy intensa, orillándose diferencias políticas ante el común rechazo a la Ley. Con el tiempo los costes políticos se atenuaron, entre otras cosas, porque Cánovas se preocupó de que las provincias vascas continuaran con un régimen peculiar, el del concierto económico, que les seguía otorgando una singularidad dentro del ordenamiento general español. Una interpretación interesada y muy extendida en el País Vasco, hace a Cánovas culpable de esa abolición, que desde esta versión no sería sino la expresión de una especie de inquina del Estado moderno hacia la singularidad de las provincias vascas. Curiosamente, si las críticas hacia Cánovas por su postura en esta coyuntura han sido y son moneda corriente, apenas hay valoraciones a la hora de juzgar la conducta de los representantes vascos. Cuando desde la historiografía se explica lo sucedido, se exponen las estrategias que ante la crisis existieron en el País Vasco - los favorables a una negociación con el gobierno frente a los contrarios-- pero no se entra a enjuiciar su eficacia, de forma que el único responsable — culpable en este caso- del desenlace por lo ocurrido fue el político malagueño. Parece a todas luces evidente que si tratamos de hacer una historia no sesgada por la enorme prepotencia de la posteridad alguna observación resulta pertinente sobre los negociadores vascos y las líneas de actuación que se desarrollaron en aquellas circunstancias. 


\section{LA ÚlTIMA GUERRA CARLISTA Y LA CRISIS DE LOS FUEROS VASCONGADOS EN 1876.}

Las Provincias Vascongadas hubieron de pagar en 1876 la cuenta de tres errores.

Luego del Convenio de Vergara, las Cortes por Ley de 25-10-1839 habían confirmado los Fueros de las Provincias Vascongadas y de Navarra «sin perjuicio de la unidad constitucional de la monarquía» (art. $1^{\circ}$ ), estableciendo que el Gobierno, tras oír a aquéllas, debía presentar un proyecto de Ley proponiendo su modificación atendiendo al «interés de las mismas, conciliado con el general de la nación y de la Constitución de la Monarquía», resolviendo entre tanto provisionalmente las dudas y dificultades que pudieran ofrecerse (art. $2^{\circ}$ ). Las Provincias Vascongadas $^{2}$, y este fue el primer error pagado en 1876, mantuvieron a lo largo de cuatro décadas una estrategia dilatoria «ad infinitum» (definida internamente en 1850 como «dar largas al negocio»), prefiriendo la comodidad del statu quo vigente, pero desaprovechando las opciones que se presentaron - en especial durante la Década Moderada - de conseguir un «arreglo» de sus Fueros razonablemente satisfactorio ${ }^{3}$. Para ello, se explotaron hábilmente la inestabilidad y el cortoplacismo del Poder central de la época, y de hecho, desde 1852, la pendiente modificación legislativa de los Fueros vascongados - señaladamente en lo relativo a la contribución económica y militar a las necesidades de la nación, sobre nuevas bases que sustituyeran a las antiguas en desuso- quedó aparcada sine die, conformándose el Gobierno con la introducción (1841-1847) de ciertas reformas puntuales de urgencia para un cierto minimum de "unidad constitucional» ${ }^{4}$. Sin embargo, algunas voces lúcidas 5 ya advirtieron en aquel momento de la equivocación que suponía «el aplazamiento indefinido» («sin duda lo más cómodo») cuando había «circunstancias favorables» y «mil medios» de obtener «una solución aceptable», pronosticando que con tal comodidad «egoísta» se dejaba «un funesto legado» a la futura generación que hubiera de afrontar indefectiblemente la modificación pendiente. Con todo acierto, afirmará posteriormente el guipuzcoano Fermín de Lasala:

\footnotetext{
${ }^{2}$ A diferencia de Navarra, que facilitó la modificación de sus Fueros por Ley de 16-8-1841.

3 Y, asimismo, mucho más respetuoso con la tradición foral -en especial en lo que hacía a sus instituciones históricas- de lo que había sido la solución navarra de 1841.

${ }^{4}$ El traslado de las aduanas interiores a la costa y frontera, la separación de las funciones administrativa y judicial, administración de justicia conforme al régimen común, derecho electoral municipal con arreglo al régimen constitucional, y desaparición de los privilegios de la «hidalguía acreditada» en los cargos públicos de las Provincias Vascongadas. Medidas, todas ellas, reclamadas al Gobierno por la burguesía comercial y progresista de las mismas provincias (señaladamente, la de San Sebastián).

s Fue el caso del alavés Blas López en 1848 , los alaveses Pedro de Egaña, Benito Ma Vivanco y el marqués de la Alameda y los guipuzcoanos Ladislao de Zavala y Francisco de Palacios en 1850, o el guipuzcoano Joaquín Calbetón en 1860 (CAJAL, Arturo: Administración periférica del Estado y autogobierno foral. Guipúzcoa 1839-1877, Oñate, 2000, pp. 614-617).
} 
«el resultado iba siendo que inevitablemente los vascongados se desacostumbraban con gusto de todo servicio. (....) Gratísima, dulcísima era así la situación euskara con esta falta de todo esfuerzo algo penoso: no lo había habido igual en el mundo; y por esto, además de ser insostenible (...) se creaba el inconveniente de que cada vez sería más penoso todo esfuerzo el día que fuera absolutamente inevitable»6.

La última guerra carlista (1872-1876), segundo y dramático error, iba a traer a primer plano de la opinión pública española la cuestión foral vasconga$\mathrm{da}^{7}$. Realmente la guerra no fue foral, sino cruzada reaccionaria-religiosa contra la revolución liberal de 1868 , pero el hecho de que las provincias vascas fueran el principal y último reducto de la rebelión, y la propia y dañina mixtificación carlista del hecho foral (es cierto que los carlistas vascos eran foralistas y hacían alarde de ello, pero no lo eran menos los liberales fueristas leales), generaron en la España liberal una identificación Fueros- carlismo objetivamente inexacta. Ahora bien, hay que reconocer que la guerra daba, al menos, un justificado motivo de recelo con respecto a aquellos: aunque la cuestión foral o la defensa de los Fueros no fueran - que no lo fueron- los móviles del alzamiento, sí era un dato obvio que las tradiciones, las técnicas y los recursos del sólido sistema foral —oportunamente adoptados por los insurrectos- favorecían aquí el desarrollo y la institucionalización de la rebelión, al proporcionarle capacidades organizativas inexistentes en otros territorios del Reino.

La consecuencia lógica de ambos errores fue que las Provincias Vascongadas hubieron de afrontar en 1876, al término de la última guerra carlista, en las peores circunstancias ambientales posibles, la tan demorada modificación legislativa de sus Fueros prevista en el art. $2^{\circ}$ de la Ley de 25-10-1839. Y se debió al legalismo de Cánovas, y su respeto a la lealtad de los liberales vascongados en la última guerra, que los Fueros fueran tratados con arreglo a la Ley de 25-10-1839, ya que gran parte de la opinión pública española la consideraba muerta de facto por la rebelión carlista (como ésta había declarado muertos los Convenios de Vergara y de Amorebieta ${ }^{8}$ ) y demandaba la pura y simple abolición foral. En esta situación se produjo el tercer error de las Provincias Vascongadas, que fue, como veremos, inclinarse por el fuerismo intransigente y negarse a toda conciliación en torno al cumplimiento de la Ley de Fueros de

${ }^{6}$ LaSala y Collado, Fermín, duque de MANDAS: Última etapa de la unidad nacional. Los Fueros vascongados en 1876, vol. I, Madrid, 1924, pp. 351-352.

7 Una muestra de ello, y del cambio ambiental que trajo la guerra, en El Imparcial (reproducido por el Diario de San Sebastián de 1-4-1876): «En efecto, El Imparcial, en 1872, no pedía la supresión de los Fueros como no la pedía el país. En efecto, El Imparcial, en 1876, pide la supresión de los Fueros. De igual modo que el país la pide también. Pero entre 1872 y 1876 median cuatro años. Cuatro años, que son un abismo donde yace la juventud liberal de España asesinada con el puñal de los Fueros».

${ }^{8}$ Este último Convenio había puesto fin a una intentona carlista -fallida- en Vizcaya en mayo de 1872 .

Hispania, LXV/2, núm. 220 (2005) 601-642 
21-7-1876, de lo que es buena muestra el testimonio del conde de Llobregat que luego se expondrá.

La Ley de 21-7-1876 se proponía cumplir el art. $2^{\circ}$ de la Ley de 25-101839 tras "tan largo espacio de tiempo", estableciendo por fin la unidad constitucional en materias económica y militar; «ha llegado indudablemente la hora de poner término a una situación insostenible. La razón lo manda, la equidad lo exige, lo pide la nación en altas voces, que sería temerario desoír, aunque fuera justo, que no lo es ciertamente», "y desvanecida la impresión del momento, que no puede menos de ser enojosa para todos los habitantes sin excepción de aquellas provincias, hasta aquí exentas de sacrificios indispensables, el Gobierno aguarda también que por todos, o por su inmensa mayoría, se reconocerá al fin y al cabo que, dadas las circunstancias en que hoy se encuentra, no ha podido proceder con más consideración, ni con más tiento, ni con mayor espíritu de justicia y de concordia que demuestra el adjunto Proyecto de

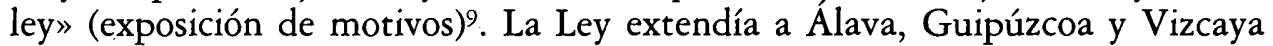
los deberes constitucionales en materias económica y militar, pero autorizaba al Gobierno a llevarlos a cumplimiento con "las modificaciones de forma que reclamen las circunstancias locales» y otras cláusulas especiales (lo que, implícitamente, daba pie al establecimiento de un sistema peculiar ad boc en estas provincias distinto del régimen común). En cuanto a las instituciones forales tradicionales, nada se decía expresamente de ellas, lo que daba pie a su continuidad, aunque también (art. $4^{\circ}$ ) el Gobierno era autorizado a establecer "todas las reformas que en su antiguo régimen foral exijan, así el bienestar de los pueblos vascongados como el buen gobierno y la seguridad de la Nación». La reforma (que no abolición) de los Fueros vascongados admitía así diversos grados posibles ... y veremos que Cánovas, durante 16 meses, va a tratar de conseguir de las instituciones forales tradicionales (Juntas Generales y Diputaciones Forales) su cooperación en el cumplimiento de la Ley, siendo la reiterada negativa de éstas la que finalmente provocará su supresión, y con ella un resultado más severo del inicialmente deseado por el Presidente del Gobierno, la desaparición del régimen foral tradicional.

Precisamente porque no era abolitorio, el proyecto de Ley fue duramente criticado en el Congreso por la oposición sagastina, deseosa de aprovechar la ocasión para hacer muy graves cargos y poner en aprietos al Gobierno ante la hipersensibilizada opinión pública española. Joaquín González Fiori, miembro de la Comisión del Congreso encargada de dictaminar sobre el proyecto, denunció que en el mismo «el principio de la unidad constitucional se desconoce» a causa de «contemplaciones excesivas o debilidades funestas», y exigió «que aquellas provincias se vean regidas por las leyes todas que gobiernan al resto de

9 Tomada de Echegaray, Carmelo: Apéndice a la obra Noticia de las cosas memorables de Guipúzcoa de Pablo de Gorosabel, vol. III, Bilbao, 1972, $2^{a}$ edición de la Gran Enciclopedia Vasca, pp. 319-322.

Hispania, LXV/2, núm. 220 (2005) 601-642 
la Monarquía», para lo cual presentó el siguiente proyecto de ley alternativo: «Las leyes políticas, administrativas y económicas que rigen en las demás provincias de España, regirán en lo sucesivo en las de Guipúzcoa, Vizcaya y Álava» (art. $1^{\circ}$ ), dando al Gobierno un plazo máximo de dos años para su ejecución $\left(\operatorname{art} .2^{\circ}\right)$. Y en el debate en pleno, las acusaciones de la minoría sagastina aumentaron todavía en gravedad. Ulloa denunciaba: "cuando se trata de provincias que en cincuenta años nos han dado dos guerras civiles horrendas, que han desangrado nuestra juventud, que nos han deshonrado ante la Europa civilizada, entonces, les decís: Administraos como queráis (...). ¿Es esto justo?. ¿Es esto político?. ¿Es esto sensato?». Por su parte, el marqués de la Vega de Armijo se lamentaba: «icuál fue la consecuencia de haber vuelto a exhumar la ley de 1839?. Encontrar, ahora como entonces, una resistencia pasiva», «el país creía que al terminarse la guerra sin compromisos, sin pactos (...), ese día sería el último de los fueros; así debía haber sucedido, y éste es el cargo gravísimo que con gran sentimiento mío tengo que hacer al Gobierno (...) desde el momento en que se resucitaba la ley de 1839 . La responsabilidad de esto pesa exclusivamente sobre el Gobierno de S.M.». Las imputaciones más duras venían en boca de Navarro y Rodrigo:

«nada de una organización privilegiada y tan refractaria al interés nacional (...) nada de una organización que le permite improvisar ejércitos, levantar empréstitos, exigir impuestos (...) porque esto sería el suicidio más grande; porque esto sería la traición más grande que podía hacerse a la Nación española. Y sobre este punto concreto interpelo al Gobierno de S.M.»10.

Así reflejaba la oposición - apropiándoselo, para intentar explotarlo contra el ejecutivo- el estado de opinión anti-foral dominante. Una vez aprobado el proyecto de Ley, y al contestar al agradecimiento transmitido por la Diputación alavesa por su defensa de los Fueros, el diputado por San Sebastián Fermín de Lasala -máximo representante del fuerismo transigente ${ }^{11}$ — expresaría que dicha «dolorosa» Ley era «resultado, sin embargo, no tan duro como el que por momentos temimos de la pertinacia de nuestros hermanos [carlistas]» (5-8-1876).

Efectivamente, conviene remontarse por un momento en el tiempo.

Desde 1869 fueron constantes las advertencias públicas, tanto de las autoridades gubernativas como de las forales, acerca del evidente peligro que para la suerte de los Fueros supondría el hecho de que precisamente unas provincias en situación excepcional como eran los territorios forales ${ }^{12}$, se convirtieran en plataforma de lanzamiento de rebelión y guerra civil.

10 Tomado de LaSala, F.: Última etapa..., cit., vol. II, pp. 16-50.

11 En sus respuestas a las Diputaciones guipuzcoana y vizcaína, Lasala recomendaba hacer frente a la situación "con los recursos que deja en pie la misma ley», porque "valerse de la misma ley» era «el procedimiento único» viable. LASALA, F.: op.cit., vol. II, pp. 73-78.

12 La observación no era nueva. Ya en 1833 el guipuzcoano conde de Villafuertes, uno de los creadores del fuerismo liberal durante la primera guerra carlista, hacía notar que las provincias 
Los representantes del Gobierno, por supuesto, lo dejaron bien claro. El gobernador civil en funciones forales Felipe Mingo, se dirigió así a las Juntas Particulares (extraordinarias) de Guipúzcoa de mayo de 1872, convocadas precisamente con motivo del alzamiento carlista acontecido ese mes (anticipo de la que será última guerra carlista ${ }^{13}$ : «No necesito llamar vuestra atención sobre el alto interés que aconseja a la Provincia evitar la reproducción de sucesos como el actual, pues demasiado comprendéis todos cuán peligroso es para vuestro porvenir el que las demás provincias de España vean partir una y otra vez de estas provincias esa especie de reto con tendencias a imponer por la fuerza principios e instituciones (...) que España condenó para siempre». Y su sucesor Isidoro Fernández Flórez reclamó en las Juntas Generales de julio de 187214 «seguridades de que este libre solar no será ya en lo futuro piedra sangrienta donde arraigue la ortiga vil de la tiranía. La lealtad de vuestro nombre, los preceptos de vuestros fueros, y el porvenir del precioso tesoro de vuestras libertades (...) así lo reclaman imperiosa e ineludiblemente».

Pero no fueron menos claras las propias Juntas y Diputaciones Forales, antes y durante la guerra. Basten dos ejemplos, en fechas tan tempranas como 1869-1870. Ya en julio de 1869, las Juntas guipuzcoanas dirigían un manifiesto «A los guipuzcoanos» ${ }^{15}$ señalando «la conducta que todos debemos seguir si aspiramos a conservar incólumes» las preciosas libertades forales: «nuestra situación excepcional nos aconseja acatar el rey que la nación española se dé en uso de su soberanía. Interesados más que ninguna otra de las provincias españolas en que la designación del monarca venga por los medios legales, los vascongados no debemos en ninguna ocasión recurrir al tumulto y a los medios de fuerza» (los destacados son nuestros). Y por poner otra muestra, el marqués de RocaVerde, Diputado General, en su proclama a los guipuzcoanos fecha 27-8$1870^{16}$, advertiría que «Guipúzcoa, que ama con pasión sus libertades, no puede prohijar los planes trastornadores que tienden a comprometerlas. Sean sus autores e instrumentos los únicos responsables de las aflicciones que causen". En sus comunicaciones internas, las corporaciones forales se mostraron igualmente conscientes del peligro cara al futuro: «Estas perturbaciones del orden que con tanta frecuencia aquí se reproducen (...) causan al país todos los males de la guerra, y concitan los ánimos del resto de los españoles en contra nuestra, pensando y con razón que respetados nuestros fueros todavía nos inmiscuimos en suscitar dificultades de gran monta a los Poderes públicos que la Nación establece en uso de su Soberanía, y en imponer nuevas obligaciones al arruinado Erario español»

vascas «eran las más favorecidas y privilegiadas, interesadas más que ninguna otra en la posesión de su bienestar por el mantenimiento del orden y sumisión a las Autoridades establecidas. Desgracia y maldición a los autores de semejante bestialidad [la rebelión carlista]». Archivo de la Casa de Zavala (en adelante ACZ), Cp. 11.1.

13 Registro de las Juntas Particulares de Guipúzcoa (en adelante RJP) de mayo de 1872, pp. 4-5.

${ }_{14}$ Registro de las Juntas Generales de Guipúzcoa (en adelante RJG) de julio de 1872, pp. 3-6.

15 RJG julio de 1869 , pp. 45-46.

16 Colección de Circulares de la Diputación Foral (CCDF) 1868-1873. 
(el Diputado General de Guipúzcoa Manuel Maximino de Aguirre a sus colegas de Álava y Vizcaya, 6-3-1873) ${ }^{17}$.

Lo anterior, únicamente por lo que hace a las advertencias oficiales de las autoridades, porque el liberalismo vascongado no dejó de mostrar la misma explícita prevención en toda suerte de expresiones. Como muestra, el manifiesto «A los electores del distrito de Tolosa» fecha 25-2-187118: «en ningún caso debe partir de nuestras libres montañas la saeta parricida que las retoñe [las heridas de la Nación]. Debemos respetar, para ser respetados»; "nuestras patriarcales instituciones, cuyo inapreciable tesoro tenemos el deber de transmitir a la posteridad. Para lograrlo nos toca dar grandes pruebas de prudencia» (los destacados son nuestros). En lógica consecuencia, ya situados a comienzos de 1876, un conocido liberal vasco advertía en su correspondencia que «la cuestión foral está casi perdida para nosotros» ${ }^{19}$.

La tempestad anti-foral de la opinión pública española desatada ese mismo año, luego de tres de guerra, no podía pillar por tanto por sorpresa al fuerismo liberal vasco, puesto que había sido claramente anunciada, y era esperada por él mismo como algo inevitable desde que aquella estalló.

A la luz de lo precedente, llama la atención que en 1876 se impusieran en el País Vasco las posiciones más beligerantes e inflexibles, cerradas a explorar las posibilidades prácticas de una negociación con el Gobierno sobre las modificaciones del régimen foral. En una coyuntura que se presentaba extremadamente difícil para la viabilidad de este último, los representantes del País optaron en buena parte por una posición de fuerza y de choque con el Ejecutivo, contribuyendo con su actividad a agravar la crisis y a cortocircuitar posibles salidas posibilistas. Desarrollaron así una estrategia de confrontación con los representantes del Estado en el momento menos favorable para hacerlo, y además situaron ese enfrentamiento en el terreno más inadecuado, como si de una lucha de principios se tratara, contraponiendo a la afirmación de Cánovas de extender a las Provincias Vascongadas «los deberes constitucionales», su firme decisión de no proceder a una modificación de los Fueros bajo tal principio. A los preceptos absolutos que defendía Cánovas ${ }^{20}$, los intransigentes, por boca de Sagarmínaga, oponían la defensa absoluta de nuestros derecbos, la no transacción en los principios absolutos ${ }^{21}$. En este choque de principios era previsible quién se iba a llevar la peor parte.

\footnotetext{
17 Archivo General de Guipúzcoa (en adelante AGG), Fondo Duque de Mandas (FDM), 82.

18 ACZ, impresos.

19 Carta de F. Machimbarrena a Lasala, 23 de febrero de 1876, AGG, FDM, 62.

20 «Este proyecto de ley [por la que será Ley de 21 de julio de 1876] contiene dos partes: precepto absoluto y autorización. Se establece como precepto absoluto que las provincias vascongadas darán en adelante los mismos hombres que dé, proporcionalmente a su población, cualquier otra provincia de la Monarquía. Se manda también que las Provincias Vascongadas den igual cantidad de contribución, contribuyan de la misma suerte en proporción a sus haberes que las otras provincias de la Monarquía». Intervención de Cánovas del Castillo en el Congreso, Diario de Sesiones del Congreso (en adelante DSC), sesión de 12 de julio de 1876, p. 2984.

${ }^{21}$ SagarmínAGa, Fidel de: "Controversias forales», en Memorias históricas de Vizcaya, Bilbao, reed. 1988, pp. 252-253.
}

Hispania, LXV/2, núm. 220 (2005) 601-642 
Surgida también en 1876 , por su parte, la tendencia transigente se nos muestra indudablemente más apegada a la realidad, y más coherente también con las clarísimas advertencias lanzadas desde 1869. Manuel de Moyua, marqués de Roca-Verde, que sería el Diputado General de Guipúzcoa hasta la renovación de la Diputación en las Juntas Generales de septiembre de $1876^{22}$ y que se veía obligado a seguir la política intransigente que en ese momento le venía impuesta, a pesar de ser uno de los representantes de la transigencia en la provincia, se sinceraba así con el diputado a Cortes Fermín de Lasala en la primavera de $1876^{23}$ : «antes de que principiara la última sublevación y no digo nada después de estallada, decíamos unánimes todos los liberales aquí, esta guerra está demente y va a ser causa no sólo de que se arruine el país, sino de que perdamos nuestros fueros (...). El hecho entonces nos parecía natural y consecuencia inevitable de nuestra rebeldía» (29-3-1876). Roca-Verde, a diferencia por ejemplo de Manuel Maximino de Aguirre (acérrimo intransigente ahora), tenía memoria.

Días antes, Lasala (diputado por San Sebastián y amigo personal de Cánovas) había escrito a la Diputación guipuzcoana informando que el Presidente aconsejaba no responder en el Congreso a los ataques anti-fueristas, para no provocar una resolución rápida y radical de las Cámaras, y le había anunciado que el Gobierno se proponía proceder con madurez, para lo cual había ya favorecido a estas provincias al no dictar disposición ninguna en medio de la agitación (21-2-1876). Roca-Verde respondería que, aunque «en mi posición oficial no me puede satisfacer nada que no sea el todo» (apuntemos, por cierto, que los intransigentes más extremistas llevarán esa defensa del todo hasta el punto de adoptar el célebre, y funesto, lema «todo o nada»), apreciaba que el Gobierno no se dejara llevar por el espíritu reinante que demandaba una resolución inmediata y drástica: «siento que todo lo que no sea resolver de plano la cuestión, es un bien para nosotros que debemos apreciar» (29-3-1876) ${ }^{24}$.

Aún con sus distintos matices, lo que caracterizaba a los transigentes era una valoración más ajustada de la situación en la que se encontraban las provincias vascas y la difícil situación de su régimen foral. Ello les llevaba a admitir la necesaria acomodación del Fuero, buscando una vía negociadora con el Gobierno de la que resultase que el País Vasco continuara disfrutando de un sistema peculiar y con evidentes ventajas. Sin embargo, veremos como sus propósitos van a resultar también fallidos.

\footnotetext{
${ }_{22}$ Roca-Verde había sido elegido en 1873, pero su relevo se había pospuesto hasta 1876 por las circunstancias de la guerra.

23 AGG, FDM, 62.

${ }^{24}$ En el mismo sentido se manifestaba Saturio de Arizmendi (Diputado General en funciones) el 14-2-1876 a Lasala: «En medio de la agitación (...) pidiendo inconscientemente la abolición de los Fueros vascongados, es consolador observar la actitud del Gobierno». AGG, ibidem.
} 


\section{LA CORRESPONDENCIA DEL CONDE DE LLOBREGAT CON CÁNOVAS.}

Javier de Barcáiztegui, conde de Llobregat por su matrimonio, había sido elegido diputado a Cortes por el distrito de Vergara en las elecciones de enero del mismo año 1876, siendo él y los demás diputados guipuzcoanos (Lasala por San Sebastián, Martín de Garmendia por Tolosa, y Francisco Gorostidi por Azpeitia), «todos fueristas y ministeriales» ${ }^{25}$. Amigo personal de Cánovas, liberal conservador y alfonsino sincero, iba a divergir en cambio de algunos de sus compañeros - y señaladamente de Lasala - en la cuestión foral, al alinearse en las posiciones del fuerismo intransigente; una intransigencia lógicamente sin extremismos y adornada con el debido tacto ${ }^{26}$, teniendo en cuenta sus circunstancias personales, pero no por ello menos clara. Varias cartas dirigidas a Cánovas ${ }^{27}$, nos proporcionan un magnífico testimonio de algunas claves de esta mentalidad intransigente, y lo erróneo de su estrategia - a partir de infundadas suposiciones y errores de cálculo-, que tan funestos habrían de ser a la postre para la continuidad de las instituciones forales tradicionales.

El argumento más recurrente de Llobregat para tratar de explicar ante Cánovas dichas posiciones no era otro, en definitiva, que la indignación moral ocasionada en el liberalismo vascongado por la durísima campaña anti-foral de la opinión pública española. «He hallado a la gente de esta ciudad [San Sebastián] (...) profundamente irritada con la prensa de esa corte y con el espíritu general que saben existe contra ellos en el interior», advertía el 26-5-1876. Pero es en su correspondencia del mes de septiembre, con motivo de las Juntas Generales de Guipúzcoa y del triunfo que en ellas obtuvo la intransigencia, donde más reiteradamente se atiene Llobregat a dicho motivo: los «ánimos tan exacerbados por la actitud de la prensa y por la atmósfera anti-fuerista que al elemento leal ha irritado al extremo por lo mismo que tanto han luchado contra los carlistas y tan mal pagados se ven por la opinión», «el ardiente espíritu fuerista de este país, excitado como dije a V. en las presentes circunstancias», «lo que ha exasperado los ánimos el apasionamiento anti-fuerista de allende del Ebro", eran señalados una y otra vez por Llobregat como gran elemento impulsor de la tendencia intransigente triunfante (9 y 12-9-1876).

Que esa indignación estaba hasta cierto punto justificada, parece indudable, teniendo en cuenta que la inexacta imputación que se hacía a los Fueros como causantes de la guerra en el Norte, y la consiguiente exigencia de su inmediata y total supresión, eran ciertamente injustas, y conllevaban además un doloroso olvido o minusvaloración de los sacrificios del liberalismo vasco, que se había mantenido leal. Ahora bien, que esa pasional indignación moral de los

\footnotetext{
25 Diario de San Sebastián, 24-1-1876.

${ }^{26}$ Lasala da con la palabra acertada al señala que «propendía a la intransigencia». LASALA, F.: Última etapa..., cit., vol. II, p. 172.

27 Escritas desde San Sebastián, y conservadas en la Fundación Lázaro Galdiano (en adelante FLG), Archivo Cánovas, legajo 4, carpeta 29.
}

Hispania, LXV/2, núm. 220 (2005) 601-642 
fueristas vascongados se convirtiera en motor de acción política, no parece, en cambio, tan lógico ni tan justificable; tanto más si se tiene en cuenta que, recíprocamente, la acción política del Gobierno Cánovas tomaba grandes distancias del anímico apasionamiento anti-foral reinante en la opinión española, adoptando una vía pausada y alejándose de una posición drástica.

Curiosamente, Llobregat admitía paladinamente que en aquel tremendamente desfavorable contexto ambiental, Cánovas constituía la única oportunidad de la causa de los Fueros de las Provincias Vascongadas: y sin embargo, se presentaba ante él con una posición intransigente que reclamaba la retirada primero, y la derogación después, de la Ley por él acuñada. La contradicción y, mucho peor, la irrealidad del planteamiento saltan a la vista, si se tiene en cuenta que Cánovas sorteaba ya duras críticas de la mayoritaria opinión más vehementemente antiforal, así como de la oposición sagastina, y que fuera del gabinete Cánovas (cuya postura en materia foral tampoco suscitaba gran entusiasmo en su propio partido), la soledad en que se hallaba la causa foral —a efectos prácticos, más allá de alguna adhesión meramente testimonial- - era espantosa.

En mayo, en efecto, Llobregat solicitaba a Cánovas que retirase su proyecto de Ley. «Pero al propio tiempo y a pesar del proyecto de ley que ha presentado V. tienen [los liberales vascongados, irritados por el espíritu general contra ellos existente] esperanza en V. y en el Rey y confían en que alargará V. las cosas todo lo posible para que este verano y antes de que no haya remedio, pueda llegarse a inteligencia y se realice la modificación de acuerdo» (26-5-1876); incluso entre los vencidos líderes carlistas, la esperanza «se cifra en su alta prudencia de V. de la que aguardan dé largas a la aprobación de esa ley para poder en el ínterin llegarse a una solución que aunque muy dolorosa sea hecha de común acuerdo, pues es evidente que tenemos que resignarnos a perder y mucho» (31-5-1876).

Es conveniente fijarse, por cierto, en las anteriores afirmaciones de Llobregat sobre la disposición a aceptar modificaciones sensibles en el régimen foral; el mismo 26 de mayo afirmaba, en el mismo sentido, que «todos [los liberales vascongados] conocen que no es posible pretender el statu quo anterior a la guerra y todos están dispuestos a grandes sacrificios». Ahora bien, ¿a qué «sacrificios» concretos, qué es lo que concretamente estaban dispuestos «a perder», para llegar a una modificación de los Fueros «de acuerdo» con el Gobierno?. Sobre esto, nada absolutamente sugiere ni apunta el conde de Llobregat a su amigo Cánovas. Silencio absoluto, que inevitablemente hace pensar en una directa continuidad con la estrategia fuerista imperante desde 1839, consistente en aseveraciones meramente retóricas de su disposición a favorecer un arreglo de los Fueros; una presunta disposición nunca concretada en datos ni hechos tangibles y positivos $^{28}$. Dicha estrategia dilatoria y de mera resistencia

${ }^{28} \mathrm{Y}$ cuando ya in extremis y por la presión de los transigentes, en abril de 1877, las Diputaciones guipuzcoana y alavesa se decidieron por fin a esbozar un proyecto de bases cara a un arreglo, lo hicieron con la propuesta de una aportación económica y militar en base a sendos cupos que serían 
pasiva, exitosa antaño en circunstancias bien diferentes, dudosamente podía tener validez en la situación de 1876.

En otra época, también había tenido éxito la estrategia liberal-fuerista de «Paz y Fueros», por la cual, bajo la alargada sombra de la primera guerra carlista (1833-1839), el fuerismo liberal había gobernado pacíficamente durante tres décadas las Provincias Vascongadas, manteniendo la lealtad de éstas a los poderes constituidos en el Reino, al tiempo que el Poder central — siempre precario, tanto en la etapa isabelina como durante el Sexenio- mantenía una política contemporizadora en materia foral. Fue la tesis magníficamente resumida en 1844 por el alavés Pedro de Egaña ante el ministro de la Gobernación Pidal: «Considere V. que la cuestión viene a reducirse en último resultado a que gobiernen el país los amantes de Isabel $2^{\mathrm{a}}$ o sus enemigos los carlistas. Dándonos V. razón en lo que pedimos (....), la posición, la influencia y el poder serán de los fueristas liberales; esto es, mandarán, conservarán la paz pública, y sostendrán y fortalecerán las buenas relaciones de las provincias con el Gobierno». Aquel fuerismo liberal, preponderantemente Moderado, absorbió o desmovilizó efectivamente al carlismo ganándolo para la lealtad a la Reina Isabel II, en clave obviamente conservadora ... pero dicha estrategia iba finalmente a saltar por los aires con la Revolución de 1868.

Pues bien, he aquí que en 1876 el conde de Llobregat va a presentarse ante Cánovas con una idea reeditora de aquella fenecida estrategia pacificadorafuerista, agitando incluso el espantajo de una hipotética confluencia subversiva carlista-republicana (y hasta de una supuestamente posible conversión republicana del carlismo vasco): «se abriga la esperanza. de que V. hombre de Estado justiciero, desapasionado y previsor no ha de querer lastimar a un país del que hoy se puede sacar grandísimo partido para consolidar esta dinastía»; «si esta cuestión [foral] no se resuelve en un momento de apasionamiento como el presente en que siempre verían un acto de venganza, no hay riesgo ninguno de que [el partido carlista vasco] se vuelva republicano. En este punto R.Z. [Ruiz Zorrilla] y demás pierden el tiempo; lo que sí es fácil, muy fácil, si ven en V. marcada resistencia y meditada lentitud en no resolver en este instante mismo la cuestión de fueros y en aconsejar al Rey una política de completo perdón como se practica en Cataluña, es que sean en breve tan monárquicos de $\mathrm{D}$. Alfonso como lo han sido de D. Carlos de quien no hay uno que no maldiga» (26-5-1876); en este tema podía hacerse «política de atracción con el partido carlista», trayéndoles a la lealtad alfonsina aprovechando su vocación monárquica (31-5-1876); «no hay es cierto el menor espíritu de rebelión pues pasó el tiempo de los levantamientos», pero «los alfonsinos de verdad somos pocos y es necesario me ayuden Vds. pues este país, profundamente desengañado de D.

ifijos e invariables!, carentes de la menor proporcionalidad y lógicamente inaceptables por el ejecutivo. Esto es todo lo que las Provincias Vascongadas llegaron a ofrecer al Gobierno. Archivo del Territorio Histórico de Álava (en adelante AHTA), D.H. 259/ 4.

Hispania, LXV/2, núm. 220 (2005) 601-642 
Carlos y que simboliza siempre sus ideas en un hombre deberá ser el baluarte invencible de la causa legítima y nuestro querido Soberano" - el mismo baluarte o puerto de refugio, apuntamos nosotros, que el País había sido efectivamente en 1840-1868 con respecto a Isabel II y al partido Moderado- (9-91876). Finalmente, «el temor de que los carlistas monopolicen en adelante la popular bandera de los fueros» era otra de las razones que Llobregat aducía para tratar de justificar ante Cánovas el triunfo de la intransigencia en las Juntas Generales de Guipúzcoa de septiembre.

Desgraciadamente para dicha estrategia, en 1876 ni el Poder central canovista padecía la crónica inestabilidad y debilidad gubernamental de las anteriores décadas, ni, lo que era mucho peor, la gestión pacificadora del fuerismo liberal vasco podía acreditarse ya con resultados. La rebelión carlista de mayo de 1872 concluida con el Convenio de Amorebieta, y el nuevo alzamiento de diciembre del mismo año (dando por fenecidos tanto éste como el antiguo Convenio de Vergara), origen de una costosísima guerra civil de tres años, habían dañado irreparablemente la credibilidad de la tesis liberal-fuerista «Paz y Fueros», tanto más cuanto esta vez la lucha se había prolongado tenazmente hasta la total derrota militar del carlismo, sin mediación de Convenio (inútilmente ofrecido por Cánovas a lo largo de 1875). Con estos lamentables antecedentes próximos, la confianza gubernamental en la virtud de los Fueros y en la capacidad del liberalismo nativo para mantener la paz en las provincias vascas, difícilmente podía ser la de 1840-1868. La última guerra carlista había sido un golpe funesto para aquella estrategia liberal-fuerista, y la idea de Llobregat de repetir la antigua fórmula de la época isabelina no parecía tener en cuenta lo diferente de las circunstancias. Cuando la situación de 1876, lamentablemente y por los desatinos del propio País, no era ni podía ser la de 1839 — como si nada hubiera pasado desde 1872 - , por desgracia Llobregat y sus correligionarios se nos aparecen, una y otra vez, nostálgicamente aferrados al recuerdo de fórmulas ya gastadas de la etapa 1840-1868.

Volviendo al proyecto canovista de modificación de los Fueros vascongados, en el mes de septiembre - durante la reunión de las Juntas Generales guipuzcoanas - lo que pedirá ya Llobregat a Cánovas será, pura y simplemente, la derogación de la Ley aprobada el 21 de julio.

El conde de Llobregat señalaba a Cánovas que «V. comprenderá que no podemos menos de sacar a salvo lo que consideramos nuestros derechos, es decir, salvar para en adelante nuestros principios «, y añadía el temor por «la falta de garantías de que sirviese para nada un sacrificio de principios dado el alcance de la ley actual y el que un ministerio siguiente al de $\mathrm{V}$. podría ejercer esta autorización en sentido radical y anular cuanto V. pudiera concedernos"(los destacados son nuestros) (San Sebastián 9-9-1876). Vemos que Llobregat recoge el argumento de la defensa de los principios para rechazar la Ley de julio de 1876 a la espera de coyunturas más favorables.

Por otra parte, si suscitaba una lógica aprensión el art. $4^{\circ}$ de la Ley que autorizaba al Gobierno a establecer «todas las reformas que en su antiguo régi-

Hispania, LXV/2, núm. 220 (2005) 601-642 
men foral [de Álava, Guipúzcoa y Vizcaya] exijan, así el bienestar de los pueblos vascongados como el buen gobierno y la seguridad de la Nación», podría pensarse que lo más realista, como mal menor, era proceder a una solución estable con Cánovas que diera formalmente a la Ley su «cumplida ejecución» (en expresión del art. $\left.6^{\circ}\right)^{29}$, y no esperar a que fuera «un ministerio siguiente» el que «en sentido radical» procediera a ejecutarla. Llama la atención, una vez más, el discutible sentido de la realidad de las tesis intransigentes.

Lo que el Presidente del Gobierno esperaba de las Juntas Generales de Álava, Guipúzcoa y Vizcaya, era que prestasen su colaboración en el cumplimiento de la Ley de 21-7-1876. A partir de ahí, podría entrarse por fin en la negociación con las Diputaciones Forales sobre el concreto modo de ejecutar la Ley (con todo lo cual, Gánovas admitía por tanto en aquel caso la continuidad de las instituciones forales históricas). Sin embargo, la decisión de las Juntas celebradas en setiembre de 1876 va a ser la contraria. Ante lo cual, habrá de conformarse con conseguir que los acuerdos junteros, aunque negasen dar cumplimiento a la Ley, al menos proclamasen explícitamente su respetuoso acatamiento de la misma, con lo cual, si bien no se resolvía el fondo del problema, consideraba formalmente salvada la dignidad de las Cortes y del Gobierno. En cualquier caso, la decisión final fue igualmente intransigente. Una vez adoptada ésta, ¿qué es lo que va a ofrecer el conde de Llobregat a Cánovas?. Veámoslo.

El día 9 de septiembre y desde San Sebastián, Llobregat le escribía que en la comisión de las Juntas de Guipúzcoa encargada de dictaminar acerca de la Ley de 21 de Julio - y de la que él formaba parte ${ }^{30}$,

\footnotetext{
${ }_{29}$ Como ocurrirá con el R.D. de 28-2-1878, primer concierto económico (y origen de un statu quo que ningún Gobierno posterior iba a suprimir, hasta 1937 durante la última guerra civil), proclamando solemnemente en su preámbulo que quedaba «así definitivamente planteada la ley de 21 de Julio de 1876» (el destacado es nuestro).

${ }^{30}$ En dicha comisión, la transigencia fue defendida por cuatro personas, el marqués de RocaVerde, el senador José Manuel Aguirre-Miramón, el alcalde de San Sebastián José A. Tutón, y el diputado a Cortes por Azpeitia Francisco Gorostidi, en minoría frente a los intransigentes, entre los que figuraba el conde de Llobregat (informe fecha 6-9-1876; correspondencia de Fermín de Lasala con Cánovas, en FLG, Archivo Cánovas, legajo 33, carpeta 18). Lasala, en su obra Última etapa... (cit., vol. II, pp. 94-97), ofrece un testimonio de la tesis transigente mantenida en la comisión por Roca-Verde, Miramón, Tutón, Gorostidi y cinco personas más: que «no se abandone al Gobierno en ningún evento la ejecución de la ley de 21 de Julio sino que la autoridad del país tome parte directa y enérgica en los actos que con aquélla se relacionan a fin de atenuar su influencia", "que se procure en todas las eventualidades salvar de nuestra organización foral cuanto sea posible», y "que el no tomar parte en la forma expuesta en los actos relativos a la ley de 21 de Julio (...)» sería dejar «en amplia libertad al Gobierno para ejecutar cuanto le acomode»; finalizando con la advertencia - tan lúcida como premonitoria- de que «todo retraimiento y todo conato de oponer la fuerza de inercia al precepto de una ley es proceder que se confunde con la inobediencia y hasta con la resistencia", y que «el sistema de apartamiento va a acarrear a la Provincia (...) la desaparición de nuestras seculares instituciones".
}

Hispania, LXV/2, núm. 220 (2005) 601-642 
«el criterio dominante en gran mayoría era (...) el de arrastrar la Junta a una intransigencia absoluta. Ante este hecho y buscando el evitar conflictos que ni al Rey ni a este país convienen conseguimos llegar a un acuerdo (...) que gracias a $\mathrm{mi}$ influencia en ella pude lograr; que por lo visto y según acabo de saber por $\mathrm{Ca}$ sado $^{31}$ no aprueba $\mathrm{V}$. sino con una precedente declaración de obediencia a la ley que yo consideraba ociosa pues es evidente que siempre se ha hablado con el respeto y acatamiento debido de todas las leyes del poder soberano (....). Más V. comprenderá que no podemos menos de sacar a salvo lo que consideramos nuestros derechos, es decir, salvar para en adelante nuestros principios, pedir la derogación de la ley, etc, pero basta que a V. no le haya gustado la fórmula para que me esfuerce en hallar otra que no le disguste y no sea una abdicación de nuestros principios (...). Yo prometo a V. lograrlo pero ayúdenos el Gobierno por su parte, que no ha sido floja la victoria que he conseguido de ánimos tan exacerbados (...). Le conozco demasiado [a $\mathrm{V}$.] para creer quisiera renuncias imposibles y si viese $\mathrm{V}$. esto vería cuánto se ha logrado».

En efecto, el día anterior el gobernador civil Casado Mata había informado al Presidente que la fórmula que tenía preparada la comisión era «que aprobándose la conducta seguida por los diputados, senadores y comisionados que han ido a la Corte y que perseverando en esta actitud, se vele por la integridad de las instituciones forales de acuerdo con las provincias hermanas", a lo que Cánovas había respondido de inmediato «no autorice V. ${ }^{32}$ que en su presencia, ni en acta o libro de actas en que $V$. haya de poner su firma, ni en ninguna forma oficial, conste la fórmula de velar por la integridad de las instituciones forales, a no ser que vaya acompañada de la expresa declaración de que se acata y obedece la ley últimamente promulgada» (8-9-1876) ${ }^{33}$. Dos días después, Casado transmitía que Llobregat gestionaba para que esa noche la comisión emitiera su dictamen ajustándose ahora al que acababan de aprobar las Juntas de Álava, y consultaba al Presidente «V.E. me dirá si lo cree suficiente, atendido el carácter intransigente que predomina en la Junta» (10-9-1876). La respuesta debió ser resignadamente afirmativa, ya que efectivamente ese dictamen - copia del acuerdo alavés - fue aprobado el día 11, sin oposición gubernativa, por las Juntas de Guipúzcoa: "hablando con el acatamiento debido», se solicitaba "reverentemente» a S.M. y a los altos poderes del Estado la derogación de la Ley de 21-7-1876, aunque se autorizaba a la Diputación «para que dentro del Fuero y de conformidad con la Ley de 25 de Octubre de 1839 pueda gestionar y resolver sobre todo lo que juzgue más útil y conveniente para los intereses de la Provincia, quedando siempre incólumes nuestros sagrados dere-

31 Laureano Casado Mata, gobernador civil de Guipúzcoa.

32 Téngase presente que el gobernador civil, en funciones forales de «corregidor político» (heredadas del viejo y multisecular corregidor del Antiguo Régimen), presidía las Juntas en representación del Gobierno de Su Majestad, con arreglo a tradición.

33 Archivo General de la Administración (en adelante AGA), Presidencia del Gobierno (PG), Asuntos Generales, caja 109. 
chos» ${ }^{34}$. Que la Ley de 21 de Julio respetuosamente se acataba y no cumplía (denegándole así, de facto, el "pase foral» que había sido formal, pero no operativamente abolido en 1841), quedaba claro ... pero una vez más, por cierto, sin precisar concretamente qué es lo que la Provincia estaba dispuesta a ofrecer al Gobierno como alternativa, para «gestionar y resolver» la pendiente modificación foral con arreglo a la Ley de 25-10-1839.

Avancemos, por cierto, que Llobregat va a recurrir, como otro argumento para intentar justificar la futura no cooperación de la nueva Diputación en la aplicación de la Ley de 21 de julio, al tradicional juramento de defensa de los Fueros que acababa de prestar la corporación entrante. Sin embargo, esta eventualidad ya había sido prevista por el Presidente del Gobierno, que el 27 de agosto comunicaba al gobernador de Guipúzcoa - con traslado a los de Álava y Vizcayaque el juramento de los Fueros se entendía sin perjuicio de la Ley de 21-7-187635; de ahí que cuando, después de las Juntas y en virtud del juramento foral que en ellas prestaron, las Diputaciones Forales se nieguen a prestar la menor cooperación al cumplimiento de la Ley, Presidencia del Gobierno emita una R.O. de 3011-1876 señalando que la celebración de las Juntas, los nombramientos hechos en ellas, y los juramentos prestados, fueron autorizados bajo la condición expresa de que todo ello se entendía sin perjuicio de la Ley de 21 de Julio ${ }^{36}$. Por otro lado, cabe tener en consideración la lógica reflexión del transigente Lasala, cuando se preguntaba si el juramento de los Fueros no se cumplía mejor preservando al régimen de su total destrucción ... ${ }^{37}$.

Lo más llamativo, sin embargo, es la forma en que Llobregat intentó presentar ante Cánovas el acuerdo de las Juntas como un éxito. Resultan sorprendentes el marcado voluntarismo y el aire de irrealidad que impregnan este último alegato del conde (12-9-1876):

«Las Juntas terminaron y no podrá $V$. quejarse de ellas, pues se adoptó por unanimidad el mismo descargo dado por las de Álava por ser este el único que había la seguridad de que le era a V. aceptable supuesto que lo había admitido en otra provincia. Aquí hay vivísimos deseos de evitar conflictos y rupturas para nadie convenientes, y no cuente V. con encontrar en la Diputación que ha elegido Guipúzcoa rebeldías de ninguna especie. No ballará $V$. cooperación para ejecutar la ley última, pues eso es imposible como $V$. conoce porque nadie practica y colabora a una política que combate y en ese caso está la Diputación foral con respecto a toda disposición anti-fuerista pero fuera de esto en que la Diputación no puede menos de defender cuanto le sea dable ${ }^{38}$ los Fueros que ha jurado al tomar parte y disolver-

\footnotetext{
${ }^{34}$ RJG septiembre de 1876, pp. 119-120.

35 AGA, PG, 109.

36 AGA, PG, 106.

37 AGG, FDM, 78.

${ }^{38}$ No sabemos hasta qué punto rechazar toda disposición anti-fuerista, y defender los Fueros cuanto le sea dable, eran compatibles con la actitud transaccional necesaria en un proceso negociador cara a la modificación foral. Al contrario, son característicos del inmovilismo puramente defensivo
} 
se la Junta, tendrá V. en ella el auxiliar más poderoso para evitar todo desorden y no apartar el país del terreno legal (...). Ya vé V. que dado el ardiente espíritu fuerista de este país, excitado como dije a V. en las presentes circunstancias (...) hemos logrado una gran victoria, fecunda a la vez para la causa del Rey y los intereses de este País (....). Cuente con plena seguridad, repito, en la lealtad y ayuda de la Diputación para mantener el país en plena y constante paz, pero no la pida V., lo que $V$. conoce muy bien no pueden hacer, cooperación en la abolición de los Fueros y como sé muy bien no puede $V$. querer semejante cosa le doy y me doy la enborabuena por lo ocurrido pues bemos dado un paso decisivo en favor de una solución prudente y pacífica " (los destacados son nuestros).

Es decir, ante un Presidente que había apostado personalmente por la Ley de 21 de Julio, que había comprometido su prestigio, que la había defendido contra una oleada de críticas abolicionistas, y que no esperaba otra cosa que tratar con las provincias la manera de llevarla a cumplimiento, iel conde de Llobregat consideraba un triunfo el acuerdo que reclamaba su derogación!. Y, para mayor asombro, el ofrecimiento de Llobregat a Cánovas ies que la Diputación Foral no iba a alterar el orden público (como si ésta no fuera su más elemental y sobreentendida obligación)!

Afirmando que «no hallará V. cooperación [en la Diputación]» para ejecutar la Ley, el conde de Llobregat ponía a Cánovas, ya en septiembre de 1876, ante la disyuntiva de derogar la Ley de 21-7-1876 o suprimir las instituciones que no iban a cumplirla, sin otra posibilidad. La intransigencia fuerista sellaba así lo que iba a suceder, aunque habrían de pasar todavía un año y dos meses de nuevos e infructuosos contactos para que, efectivamente, perdida toda esperanza de una conciliación, el Presidente del Gobierno procediera a fines de 1877 a resolver la cuestión suprimiendo las Juntas Generales y Diputaciones Forales tradicionales, que, dada su negativa a cumplir la Ley de 21-7-1876, no juzgaría ya merecedoras de continuidad en el régimen de Conciertos Económicos nacido en 1878.

\section{LAS RESPONSABILIDADES DE CÁNOVAS.}

El año y medio que discurrió desde las primeras negociaciones en mayo de 1876 entre Cánovas y los comisionados vascos hasta la supresión de los organismos forales en noviembre de 1877 , fue una etapa marcada por la tensión entre el ejecutivo y las instituciones del País Vaco, con una pugna a veces sorda y en otras abierta entre ambas partes. Situada la confrontación en el terreno de los principios era difícil llegar a puntos de acuerdo, sobre todo cuando el principal punto de litigio era una Ley que los representantes vascos rechazaron y

que venía rigiendo la actitud fuerista desde 1839 , ante toda novedad que entrara a modificar el régimen foral tradicional.

Hispania, LXV/2, núm. 220 (2005) 601-642 
obstruyeron hasta donde pudieron en su aplicación. Durante este tiempo se pusieron en práctica dos estrategias, y mientras Cánovas buscaba una aplicación pausada de la Ley de 21 de julio con la finalidad de ir minando las posiciones más duras y ganarse voluntades en el País Vasco, desde las instituciones del País se pretendió, sobre todo, dilatar el proceso e impedir la entrada en vigor de la Ley en espera de tiempos mejores. En este contexto, la actuación de Cánovas aparece con más matices que la imagen simple y férreamente agresiva hacia el País Vasco con que a veces es presentado. Detengámonos sobre este punto.

La actuación del político malagueño en esta coyuntura respondió a un objetivo preciso: que las provincias vascas dejaran de mantener lo que él entendía era una situación de privilegio y pasaran a contribuir al Estado tanto en el terreno fiscal como en el servicio militar. Pensaba Cánovas que la condición de provincias exentas que disfrutaban las provincias vascas era extraordinariamente injusta, y no se correspondía con el desarrollo y evolución de las naciones. Dicho con sus propias palabras:

«Todo aquello que signifique desigualdad entre un español y otro español está destinado a sucumbir por obra del tiempo y de la Providencia, por la ley de formación de las nacionalidades, por el principio de asociación que reúne a los individuos de las Naciones entre sí y que impide que en esas asociaciones haya individuos de desigual condición y que sigan desiguales fortunas» 39 .

Fue taxativo y diáfano en la aplicación de este criterio, que lo planteó como una cuestión de Estado, no debatible y que los vascos habían de asumir. De este modo, en las reuniones que celebraron Cánovas y representantes de las tres provincias vascas previas a la Ley de julio, el Presidente del Gobierno sentó como punto de partida la idea de extender al País Vasco los deberes constitucionales, lo que suponía la implantación de la contribución fiscal y militar, y como él mismo dijo, sobre este punto no estaba dispuesto a negociar con los comisionados vascos, sino sólo a oírlos ${ }^{40}$. Precisamente Fermín de Lasala, como ya hemos indicado correligionario de Cánovas e íntimo amigo suyo ${ }^{41}$, criticó su dogmatismo doctrinal y su falta de tacto al colocar esta cuestión como primer punto ${ }^{42}$, creando de inicio un obstáculo difícil de superar, a la par que daba aliento a la intransigencia vasca frente a los partidarios de la negociación. Siendo esto así, ello no quiere decir que Cánovas mantuviera una posición rígida a lo largo de esta coyuntura, ni que su intervención estuviera guiada por un celo ultracentralista del que en ocasiones se le acusa. Para empezar, y como ya se ha di-

\footnotetext{
39 Intervención en el Congreso, sesión de 12 de julio de 1876, DSC, p. 2985.

${ }_{40}$ Discurso en el Congreso, sesión 17 de julio de 1876, DSC, p. 3161.

41 Véanse LASALA, F.: Última etapa..., cit., vol. I, p. 492; y su discurso en el Congreso el 18 de julio de 1876. En la réplica de Cánovas en la Cámara dice que él no pretendió la conformidad de los representantes vascos con el principio por él sostenido de la unidad constitucional, sino la sumisión.

${ }^{42}$ LASALA, F.: op.cit., vol. I, pp. 482 y ss.
} 
cho, Cánovas no se dejó llevar por el clima antifuerista predominante en la política española, que pedía la simple nivelación de las provincias vascas. Además, en reiteradas ocasiones, Cánovas expuso su ánimo de negociar las condiciones en las que el País Vasco debería hacer efectivas sus contribuciones, declarándose dispuesto a estudiar aquellas fórmulas que resultaran ventajosas para estas provincias. Pero, quizás más importante, consideraba que con la Ley de 21 de julio de 1876 no se abolían los Fueros, sino que se «modificaban»y, por tanto, éstos continuaban subsistiendo. Prueba de ello fue la continuidad de las instituciones forales, que hasta su disolución llevaron una intensa vida. Se mantenía de esta manera una base ciertamente importante del régimen foral, que la intransigencia vasca no apreció suficientemente.

Los propósitos de Cánovas de negociar la forma como se podían aplicar las «modificaciones» chocaron con las instituciones vascas que alineadas, por lo general, tras posiciones intransigentes, rechazaron la Ley de julio en tanto interpretaban que suprimía el régimen foral. En ese contexto de confrontación, Cánovas actuó con astucia en unas provincias levantiscas y con un Estado todavía relativamente débil. No buscó la abrupta aplicación de la Ley, que podía ocasionar una mayor hostilidad hacia el Gobierno, sino que actuó con prudencia con el objeto de encontrar apoyos en el País y de ahondar las fracturas internas, a la vez que mantuvo frecuentes reuniones con representantes vascos con el objeto de desbloquear la situación. De este modo, por ejemplo, a la altura de setiembre de 1876, Cánovas exponía que había suspendido la publicación de un plan de contribuciones del Ministro de Hacienda "por si queda alguna esperanza que procediendo despacio y ponderadamente se obtiene alguna ventaja importante» ${ }^{43}$. En esos contactos, Cánovas formuló una serie de propuestas a la parte vasca a través de las cuales se puso de manifiesto que para él la cuestión central era fijar una fórmula estable de contribución económica para estas provincias, siendo el cupo militar de importancia menor, a la par que afirmaba su voluntad de mantener la peculiaridad administrativa de las provincias vascas y sus organismos forales. Así, a través de esas reuniones, en las que el conde de Llobregat continuó desempeñando una función relevante como intermediario, Cánovas reiteraba «sus disposiciones benévolas para un arreglo conveniente a todos; en que sólo quería la contribución directa, más reducida que la fijada como tipo por el sr. Bravo Murillo ${ }^{44}$, admitiéndose en descargo de ésta los gas-

43 AGA, PG, 109, telegrama de Presidencia a Quesada, general en jefe del Ejército del Norte, 2-9-1876.

44 En 1852, bajo la presidencia de Bravo Murillo, se habían presentado a los comisionados vascos dos proyectos de modificación de los Fueros, el primero de los cuales entraba a concretar el "cálculo de lo que deberán satisfacer las Provincias Vascongadas en equivalencia de las contribuciones y rentas que cargan sobre las demás provincias del Reino», del cual habría que descontar las cantidades que las Provincias Vascongadas invertían en determinadas materias que, en el resto del Reino, correspondían a los presupuestos generales del Estado (culto y clero, etc) (AGG, FDM, 60). Más detalles en VÁzQUEZ DE PRADA, Mercedes: Negociaciones sobre los Fueros entre Vizcaya y el poder central, 1839-1877, Bilbao, 1984, pp. 209-211 y 483-492.

Hispania, LXV/2, núm. 220 (2005) 601-642 
tos generales ${ }^{45}$. Que él está dispuesto a hacer todas las concesiones posibles en beneficio del arreglo, y que una vez hecho, los Gobiernos que se sucedan lo respetarán» ${ }^{46}$. En cuanto al tema del servicio militar, entre las varias propuestas que se formularon, Cánovas admitía que «si no pueden hacer la quinta pueden pagarla (....); tendría para ustedes la ventaja inmensa de que ha quedado sentado el precedente de que hubiesen mozos y para mí el poder decir a las Cortes que la Ley estaba cumplida y el año que viene Dios dirá» ${ }^{47}$.

Esta política de flexibilidad por parte de Cánovas se combinaba con unas posiciones de mayor dureza, en las que dejaba patente que el objetivo que le guiaba era la aplicación de la Ley de julio y que sobre los términos contenidos en dicha ley no estaba dispuesto ni a convenios ni a pactos ${ }^{48}$. La resistencia pasiva que opusieron las instituciones forales a la ejecución de la Ley, forzaba a Cánovas a no descuidar esa imagen de firmeza y adoptar medidas coactivas como el mantenimiento de la suspensión de las garantías constitucionales en estas provincias - situación que se mantuvo hasta 1879-, o la incautación de las cajas de las haciendas provinciales ante su rechazo a hacerse cargo de un impuesto, o bien la aplicación de distintas sanciones ante la negativa a cumplimentar el alistamiento militar. En esa misma dirección, Cánovas recordó en diversas ocasiones el estado de guerra vigente en estas provincias ${ }^{49}$, amenazó con destituciones o restricciones al uso del término «foral» a las diputaciones, así como trató, sin mucho éxito, de restringir los movimientos de estas corporaciones. Además, da la impresión que en alguna ocasión se vio desbordado por alguna iniciativa adoptada desde sus propias filas, y por algunas actitudes particularmente conciliadoras de su delegado en las provincias vascas, el general en jefe del Ejér-

\footnotetext{
${ }^{45}$ En referencia a algunos gastos que se consideraban propios de la Hacienda del Estado en el régimen común del resto de España, y que en las Provincias Vascongadas eran voluntariamente asumidos como propios por las Haciendas forales (sostenimiento del culto y clero, etc.)

${ }^{46}$ De la reunión mantenida entre Cánovas y comisionados vascos, 16 de diciembre de 1876 Archivo Diputación Foral de Bizkaia (en adelante ADFB), Archivo Administrativo, Gobierno, J00264,. También en LASAlA, F.: Última etapa..., vol. II, p. 141. En este mismo mes diciembre Cánovas, a través del conde de Llobregat, traslada una oferta con dos alternativas, exponiendo en la segunda de ellas que "Yo no haré más que lo que de todos modos quiero, es decir, no sacaría sino la contribución directa y dejaría la administración provincial con los consumos en que ésta se funda a la Diputación Foral que funcionaría independientemente y separada.» A cambio Cánovas venía a pedir lealtad institucional. En ADFB, J-00264, 28 de diciembre de 1876.

47 Carta del conde de Llobregat al Diputado General de Guipúzcoa Juan Bautista de Acilona dándole cuenta de lo conversado con Cánovas, 14 de enero de 1877. ADFB, J-00264.

48 "Me he visto obligado a desmentir las noticias sobre convenio: que para cortar errores perjudiciales haga entender que el Gobierno no celebrará convenio ni nada que parezca pacto con las provincias, siendo lo único que puede hacer entrar en los arreglos previstos en la Ley de 21 de julio...». Telegrama de Presidencia de Gobierno a los gobernadores, 17 de febrero de 1877, AGA, PG, 109.

49 Debido, en principio, a la todavía reciente terminación de la guerra carlista, y a las conspiraciones carlistas y republicanas que seguían tramándose para reiniciarla, permanentemente vigiladas por el general Quesada (AGA, PG, 105, 108).

Hispania, LXV/2, núm. 220 (2005) 601-642
} 
cito del Norte Genero de Quesada ${ }^{50}$. Éste formuló, en febrero de 1877, unas bases de entendimiento bastante favorables a la parte vasca, que en lo sustancial contemplaban la continuidad de los organismos forales y una contribución única para el Estado, puntos muy bien vistos por los transigentes ${ }^{51}$. Inquirido por su criterio acerca de esta propuesta, Cánovas respondió con habilidad, incidiendo en las posibilidades que abrían, pero también marcando cierta distancia ${ }^{52}$.

En cualquier caso, Cánovas era consciente de la necesidad de ganarse a sectores de la sociedad vasca ya no sólo para lograr la efectiva aplicación de la Ley de julio, sino, incluso más importante, para no generar una foco de permanente conflicto. Por ello, sus ofrecimientos y señuelos fueron constantes, si bien tales "ventajas" estaban condicionadas a que las instituciones forales "coadyuvasen" con el ejecutivo ${ }^{53}$, y en tal caso no se cansaba de repetir que «si aquel país se presentara obediente yo le haría grandísimas concesiones» ${ }^{54}$. Era una estrategia con dos caras, el palo y la zanahoria ${ }^{55}$, marcada por la necesidad de amortiguar el descontento que en el País Vasco había originado el nuevo estado de cosas y más en particular las exigencias fiscales y militares que ahora se le demandaban. Cánovas sabía que el tiempo jugaba a su favor y que los vascos no mantenían posturas homogéneas y jugó con estos factores, aplicando una táctica de desgaste, con la que fue minando a sus oponentes y profundizando en sus divisiones. Trató de ganarse el apoyo de las instituciones forales, pero ante su fracaso, las fue eliminando, primero, en mayo de 1877 , las de Vizcaya, que encar-

so Sobre Quesada y lo acaecido durante estos meses, véase CAJAL, Arturo: «Pensamiento del general Quesada durante la crisis de los Fueros vascongados (1876-1877). Su correspondencia con Cánovas», en Historia Contemporánea (en prensa).

51 Para esta iniciativa, el artículo antes citado de Cajal, así como Vázquez de Prada (Negociaciones..., cit., pp. 381-383), y el imprescindible Lasala (Última etapa..., cit., vol. II, pp. 158 y ss.) que recoge información de primera mano que se localiza en su archivo (AGG, FDM, 62); así como el AGA, PG, 104 y 109.

52 En un telegrama del día 9 de febrero señalaba que esas bases «me parecen excelentes en principio y como bases de discusión, y que creo que partiendo de ellas llegaríase fácilmente a un arreglo satisfactorio», pero había comenzado diciendo que «debo recordar a V. (...) que yo no he aceptado de un modo definitivo las bases de arreglo que $\mathrm{V}$. me remitió últimamente, porque para eso es indispensable un examen más profundo y detenido del que he estado hasta ahora en el caso de hacer...». AGA, PG, 109, y LASALA, F.: op.cit., vol. II, pp. 163-164.

53 El general en jefe del Ejército del Norte, Quesada, hace saber a las tres Diputaciones «que si estas corporaciones coadyuvaban con buena voluntad al cumplimiento de la Ley de 21 de julio se interpretaría del modo más favorable que su letra y espíritu permitiesen y podrían las provincias mantener su Administración actual y pagar bajo un sólo concepto si así lo preferían». 1 de diciembre de 1876. ADFB, J-00263.

${ }^{54}$ Sigue el texto: " no sólo en la cuestión de impuestos en cuyo punto me contentaría con el equivalente a la contribución directa, tomando por tipo de ella no el $21 \%$ que es la actual sino el 12 o el $14 \%$ y aún en este caso con rebajas por muchos conceptos...». Carta del conde de Llobregat a Acilona ya citada del 14 de enero de 1877.

ss AlONSO OlEA, Eduardo: El Concierto Económico (1878-1937). Orígenes y formación de un derecho bistórico, Oñate, 1995, p. 44. 
naba la línea más dura de la intransigencia, sin que tal medida produjera reacciones significativas en las otras dos provincias. Ya desde una posición de fuerza, optó por disolver en noviembre-diciembre de ese año las Diputaciones Forales de Álava y Guipúzcoa ante el hecho de que no había posibilidades de llegar a un acuerdo en el tema fiscal y ante su reiterado rechazo a la Ley de julio ${ }^{56}$. Se entraba en una nueva fase con unas Diputaciones bajo la ley general, ya «Provinciales», cuyos componentes fueron designados por el Gobierno, si bien al poco fueron dotadas de nuevas funciones que las distinguirán de las demás del Reino.

Uno de los elementos en que se refleja cómo transcurrieron aquellos sucesos, es que entre los propósitos iniciales de Cánovas no entraba esa supresión de las instituciones forales, sino que en su ánimo estaba su mantenimiento. Todavía en mayo de 1877 , justo un año después de las primeras reuniones que ambas partes habían celebrado, en una reunión de comisionados guipuzcoanos y alaveses con Cánovas, aquéllos señalaban que en cuanto a «la Administración del País (...) manifestó no encontraba dificultad que ésta siguiera en su organización y funciones cual siempre», y uno de los comisionados suscitó «la palabra autonomía administrativa, sin que (el Presidente) la rechazara y aun alguno haber creído oír que la repetía él mismo» ${ }^{57}$. No representaba, en cualquier caso, ninguna novedad en las posiciones que había sostenido Cánovas. Durante la discusión de la Ley de julio en el Congreso, en momentos de una intensa efervescencia antifuerista fuera del territorio vasco, Cánovas expuso con claridad que él pretendía, sí, establecer la «unidad constitucional» y, por tanto, la obligatoriedad de los vascos de contribuir como los demás habitantes del reino, pero también cómo había que «mantener en aquellas provincias el espíritu administrativo en que indudablemente han sido superiores hasta ahora a otras de la Nación ' $^{58}$.

Unos días después, en el mismo solemne lugar, Cánovas expuso su doctrina respecto a la organización de la nación y la situación que podían disfrutar las provincias vascas. Se mostraba en este punto como un decidido partidario de la «unidad política», de la centralización de la nación y de que el Estado estuviera presente de una manera efectiva en el conjunto del territorio.

«Yo creo en la unidad del poder político, en la necesidad de la unidad en el gobierno, en la necesidad de que la autoridad Real llegue a todas partes, de que

\footnotetext{
$56 \mathrm{El}$ motivo concreto fue la negativa de las instituciones forales a "cooperar» al cumplimiento de un R.D. en el que se fijaban las cantidades que las provincias debían pagar por «inmuebles, cultivo y ganadería", habiéndose expresado asimismo en esas protestas de las autoridades forales su rechazo a la Ley de julio.

57 Resumen de la conferencia celebrada el 19 de mayo. ATHA D.H. 259/4.

${ }^{58} \mathrm{Y}$ sigue así el discurso: «espíritu que es de deplorar que en otras muchas no exista, y que después de todo sería a mi juicio absurdo destruir, cuando es y debe ser aspiración de todos nosotros (...) irlo llevando y aplicando a todas las demás provincias sin distinción de la Nación española». Sesión de 12 de julio de 1876, DSC, p. 2985.
}

Hispania, LXV/2, núm. 220 (2005) 601-642 
en todas partes se ostente como título la autoridad Real (...).Yo he sostenido hasta ahora constantemente la necesidad de que el Gobierno no se descentralice, de que el principio de Gobierno llegue a todas partes, de que los agentes del Gobierno no puedan en ninguna parte ser contrarios al estímulo, al impulso, a la dirección del Poder Real, ejercido por sus Ministerios responsables».

Pero a continuación añadía su respeto por la «descentralización administrativa», que consideraba que era un sistema beneficioso, como se podía ver en el caso de las Provincias Vascongadas, por lo que éstas, por tanto, debían mantener en alguna forma ese régimen peculiar que disfrutaban. Decía Cánovas:

«Pero en cuanto a la descentralización puramente administrativa, yo no he tenido nunca más que una sola opinión; yo no he tenido más que un sólo sentimiento; y es el dolor de ver la legislación francesa pesando como ha pesado sobre este país y quitándonos como nos ha quitado de esa manera una escuela de administración, una escuela de libertad y grandes medios que hoy mismo se aprovecharían para el establecimiento definitivo del régimen constitucional.

(...) Yo aunque interrumpa la uniformidad administrativa de mi país no trataré de destruir esa descentralización provechosa. Bien conozco la dificultad de extender esa reforma a todo el país cuando se trata de provincias niveladas (...); pero cuando hay provincias donde la descentralización administrativa existe, y cuando según dije el otro día debe ser este el ideal del Gobierno, cexige la lógica que lo destruyamos a fin de tener que restablecerlo por un Real decreto mañana?»59.

Era un tipo de ideas que habían sido ya expuestas unos pocos años antes, en un texto frecuentemente citado, donde Cánovas exponía que él era contrario a "privilegios que redundan en menoscabo de lo demás de España», pero

«por descontado, que nada de lo que acabo de decir sobre los privilegios, se extiende a la autonomía local, al peculiar régimen administrativo, al organismo interior, en fin, de ninguna de las tres Provincias vascongadas. Lejos de desear que desaparezcan de allí instituciones semejantes, querríalas yo comunicar, si fuera posible, al resto de España» 60.

La posición de Cánovas en este punto encajaba con la trayectoria mantenida por el moderantismo español a lo largo del siglo XIX que había visto «el régimen fuerista como la realización de la utopía conservadora» y aceptado que estas provincias fueran un «oasis» descentralizado en un sistema que trataba de dotarse de una organización centralizada ${ }^{61}$. Las tesis que sostuvo Cánovas en

59 Sesión de 17 de julio de 1876, DSC, p. 3163.

60 Introducción de Cánovas a RODRígueZ-FERRER, Miguel: Los Vascongados, Su país, su lengua y el príncipe L.L. Bonaparte, Madrid, 1873, p. XII.

${ }^{61}$ PÉRez NúNEZ, Javier: La Diputación Foral de Vizcaya. El régimen foral en la construcción del Estado Liberal (1808-1868), Madrid, 1996, pp. 638-639. 
esta coyuntura acerca del País Vasco no hicieron sino materializar su pensamiento acerca de la nación, que se caracterizaba por una visión pragmática, conservadora $^{62}$, y en cierta manera tradicionalista. Entendía Cánovas que las naciones estaban sustentadas en la historia, eran una producto de una evolución, de un hecho "divino» o "natural» que debía quedar a salvo de toda decisión individual o colectiva ${ }^{63}$. En este enfoque de corte historicista y organicis$\mathrm{ta}^{64}$ se primaba aquello que se entendía que era secular, que tenía un largo recorrido histórico, lo «interno» de cada nación, frente a los valores modernos, estimados como de condición inferior. Defensa, pues, del «principio monárquico" y del "principio hereditario» en tanto que dos principios que han subsistido en la historia de España, y rechazo, en cambio, de la idea de que los individuos puedan forjar la nación, y, como su extensión, del sufragio universal que lleva inevitablemente al socialismo ${ }^{65}$. Dicho en palabras actuales, en caso de conflicto, lo histórico, lo originario, había de prevalecer sobre la constitución escrita, sobre el poder de la sociedad de autodeterminarse. Planteamientos, por otra parte, muy similares a los sostenidos por la «intelligentsia» vasca del s. XIX en su defensa del Fuero, que empleaba la historia como base de la legitimidad del sistema foral por lo que aquélla representaba de encarnación de la tradición ${ }^{66}$.

Armado con estas ideas, aquí muy sumariamente expuestas, no puede extrañar que Cánovas sintiera simpatía hacia el régimen de estas provincias, al fin y al cabo ejemplo de un sistema de profundas raíces históricas y que había sido administrado desde unos principios conservadores, con los que se identificaba Cánovas.

Tales postulados se compaginaban con la defensa por Cánovas de unos principios unitaristas, en la creencia de que la humanidad camina hacia las grandes agrupaciones nacionales y en ese proceso los pequeños estados tenían escasa viabilidad. Pero para que esas naciones pudieran progresar adecuadamente, era conveniente que existiera un «común espíritu», que se hubiera realizado «lenta y solitariamente (...) la unificación de los sentimientos y las ideas», mostrándose, por tanto, reticente a la diversidad que albergaba, por ejemplo, el Imperio Austro Húngaro ${ }^{67}$. Mas esa defensa de un modelo centralizado debía tener un freno y era el respeto a lo tradicional, a aquellos elementos de base histórica que exis-

62 Véase DardÉ, Carlos: «Cánovas y el nacionalismo liberal español», en Nación y Estado en la España liberal, Madrid, 1994, p. 218.

63 «No, señores, no; que las naciones son obra de Dios, o, si alguno o muchos de vosotros lo preferís, de la naturaleza. Hace mucho tiempo que estamos convencidos todos de que no son las humanas asociaciones contratos, según se quiso un día; pactos de aquellos que, libremente y a cada hora, puede hacer y deshacer la voluntad de las partes.» En Discurso sobre la Nación. Ateneo de Madrid, 6 de noviembre de 1882, edición de Biblioteca Nueva, Madrid, 1997, p. 107.

${ }^{64}$ Sobre esta concepción de Cánovas, por ejemplo, Pérez GARZÓN, J. S.: «El debate nacional en España: ataduras y ataderos del romanticismo medievalizante», en Ayer, $\mathrm{n}^{\circ} 36,1999$, pp. 165-166.

65 Véase CánOvas del Castillo, Antonio: Discursos Parlamentarios, Madrid, 1987, pp. 215 y 291.

${ }^{66}$ Clavero, Bartolomé: «Estado de jurisdicción e invento de la Constitución», en La cuestión vasca. Una mirada desde la bistoria, Bilbao, 2000, p. 21.

${ }^{67}$ CánOvas, A.: Discurso sobre la Nación..., cit., pp. 99 y ss. 
tieran en el territorio, que debían ser promovidos e incorporados como un patrimonio de la nación. De nuevo Cánovas juega con el binomio de lo antiguo y lo moderno, elogiando a "Naciones como Inglaterra y Alemania (...) que no se avergüenzan de conservar grandes restos de la Edad Media al lado de los mayores adelantos de nuestro siglo; las Naciones que no pretenden la uniformidad...», en tanto que rechaza el modelo que representa Francia que con su búsqueda de la «homogeneización y de la simetría» causa «una obra de verdadera perdición» ${ }^{68}$. Apego, pues, por los países y modelos sustentados en la tradición y distanciamiento de aquellos otros que como Francia encarnan, con sus vaivenes, una tradición revolucionaria. En este sentido, Cánovas simpatizaba con aquellos procesos de construcción nacional que se estaban dando en Europa que tendían a recoger (como Alemania) derechos particulares de sus territorios, frente a los que (como Francia) se levantaban en oposición a las peculiaridades provinciales ${ }^{69}$.

Dadas estas ideas no puede sorprender el doble movimiento que promovió Cánovas con respecto a las provincias vascas, reforzando, por un lado, la cohesión de la nación española a través de la supresión de lo que entendía eran los privilegios que disfrutaban estas provincias y poniendo en pie una Constitución (la de 1876) de corte unitarista, a la par que, por otro, articulaba una alternativa en clave administrativista que permitía a estas provincias mantener un régimen peculiar. Materializaba de esta manera lo que muchos historiadores han considerado como una vía de "compromiso», de «equilibrio" y «transacción» que caracterizaría a Cánovas ${ }^{70}$, una fórmula intermedia entre las posiciones simplemente niveladoras y las que pedían la intangibilidad del Fuero. Porque, en efecto, una vez suprimidas las instituciones forales, Cánovas se apresuró a convocar a unos nuevos comisionados vascos, ahora emanados de las diputaciones provinciales de carácter transigente, con los que negociar la aplicación de la Ley en lo que atañía a las cantidades a aportar y la fórmula para hacerlo. Reuniones no exentas de discrepancias que en este artículo no es el caso $\operatorname{tratar}^{71}$, pero en las cuales se plasmó lo que en su transcurso expuso Cánovas acerca de «que sentado el principio de la aplicación de la Ley de 21 de julio estaba dis-

${ }^{68}$ CÁnovas, A.: Discursos Parlamentarios, cit., p. 293. Forma parte de un discurso pronunciado el 17 de noviembre de 1876, en plena polémica por la situación en las provincias vascas.

69 BRUBAKER, Roger: Citizenship and Nationbood in France and Germany, London, 1992, p. 12. Posteriormente ha matizado la distinción entre nacionalismo cívico y étnico presente en este trabajo. Véase, «Mitos y equívocos en el estudio del nacionalismo», en HALL, John A., Estado y nación, Madrid, 2000 , pp. 390 y ss.

70 Entre otros, FUSI, Juan Pablo: El problema vasco en la II República, Madrid, 1979, p. 16; VÁzQUEZ DE PRADA: Negociaciones..., cit., CAJAL: Administración periférica..., cit., $\mathrm{M}^{\mathrm{a}}$ Cruz Mina, Ignacio Olábarri, etc.

71 VÁzQUez de PRADA, Mercedes: «Del régimen foral al concertado: la negociación del primer Concierto Económico (mayo 1877 -febrero 1878)», en Revista Vasca de Administración Pública, nº 8 , 1984, pp. 91 y ss. Alonso Olea, E.: El Concierto Económico..., cit.

Hispania, LXV/2, núm. 220 (2005) 601-642 
puesto a favorecernos en cuanto le fuera posible en la parte con que habíamos de contribuir ${ }^{72}$. Fruto de, ahora sí, esas negociaciones, fue el primer concierto económico a través de un R.D. de 28 de febrero de 1878 que de momento reportaba indudables ventajas económicas ${ }^{73}$, pero que además abrió una vía para que las provincias vascas pudieran consolidar un régimen peculiar. Así ocurrió, y lo que en principio no era más que un concierto económico con minúsculas y entendido en el sentido de integrase en el concierto (ordenamiento) económico de la nación ${ }^{74}$, fue deviniendo en un sistema con amplias atribuciones para las provincias vascas que daba cobertura a su singularidad y les diferenciaba del resto de España ${ }^{75}$. Con el paso de los años y el asentamiento del nuevo régimen, Cánovas no cambió su criterio, y con ocasión de la primera renovación del Concierto en 1887, el político malagueño, entonces en la oposición, hizo saber a los comisionados vascos que él entendía que las provincias vascas debían regirse por «disposiciones especiales distintas de las demás del Reino", aunque en esas fechas se mostraba reticente a la vuelta de los antiguos organismos forales ${ }^{76}$.

\section{LAS ESTRATEGIAS DE LOS REPRESENTANTES VASCOS ${ }^{77}$.}

Llegados a este punto, nos parece conveniente volver sobre el comportamiento de los representantes vascos con objeto de poder dilucidar sus diferentes líneas de actuación. Como se ha venido observando, la postura de los vascos distó de ser homogénea o unánime. Hubo, sí, un lamento general por la ley de julio, y las críticas a Cánovas, con distinto énfasis, fueron moneda corriente, creándose un clima de descontento con respecto a la política del Gobierno, que se tradujo en que las posiciones más críticas con el ejecutivo tuvieran un mayor calado. Era una atmósfera que propiciaba el desarrollo de posturas «intransigentes", donde lo predominante eran las posiciones de rechazo contundente de la Ley de julio en tanto que aquellas que buscaban puntos de encuentro con el

72 Extracto de la reunión entre Cánovas y representantes vizcaínos, diciembre 1877, ADFB, J02270/013.

73 Así lo reconocía el propio Cánovas en el Congreso cuando señalaba que «sería imposible dejar de reconocer que hoy están aquellas provincias muchísimo menos recargadas de impuestos que las demás». Sesión de 11 de diciembre de 1878, DSC, p. 4023.

74 En la exposición del R.D. de 28 de febrero de 1878, se indicaba que «Establecida la unidad constitucional en las Provincias Vascongadas (...) faltaba sólo que entrasen aquéllas en el concierto económico; faltaba que cuantas manifestaciones tributarias se consignasen en los presupuestos generales del Estado (...) afectasen de igual modo a los naturales de aquel país...».

75 Por expresarlo gráficamente, se fue pasando de la primera acepción que el diccionario de la Real Academia le da al término «concierto» («Buen orden y disposición de las cosas»), al segundo («Ajuste o convenio entre dos o más personas o entidades sobre alguna cosa»).

76 Reunión el 18 de enero de 1887. Archivo General de Gipuzkoa, JDT, 1841.5

77 Una descripción rigurosa y detallada del proceso que exponemos en este epígrafe, en VÁzQUEZ DE PRADA, M.: Negociaciones..., cit. 
ejecutivo nadaban contra corriente. En este sentido, las posiciones transigentes tuvieron que actuar en un marco poco propicio, de lo cual se resintieron a la hora de tomar posiciones públicas.

En cualquier caso, y como ya se ha ido viendo, los representantes vascos pusieron en liza diferentes estrategias marcadas por la línea divisoria entre los intransigentes, que rechazaban la Ley de julio a la que consideraban como abolitoria de los Fueros y se negaban a negociar con el Gobierno sobre esta base, frente a los transigentes, que asumían una postura más realista que pasaba por tratar con el ejecutivo la consecución de unas condiciones lo más favorables para las provincias vascas.

Aunque la intransigencia se impuso, las cosas no fueron tan sencillas como a veces se presentan. En primer lugar, la intransigencia no tuvo el mismo calado en las tres provincias, siendo en este punto Vizcaya la que encarnó la línea más dura frente a la mayor moderación de las otras dos. Así ya con ocasión de las reuniones de los comisionados de las tres provincias con Cánovas en mayo de 1876, el Diputado General de Guipúzcoa señalaba cómo Álava y Guipúzcoa estaban dispuestas a arreglos en la cuestión de hombres y dinero, pero no así Vizcaya ${ }^{78}$. Una prueba de la firmeza de esta provincia la tenemos en que en una de las reuniones que paralelamente celebró la Comisión extraordinaria de Fueros de Vizcaya, solamente uno de sus componentes se manifestó partidario de que se negociara «procurando sacar el mejor partido posible en la modificación que el Gobierno trata de introducir», siendo replicado por los diputados generales que «dijeron que ambos estaban decididos a resignar el honroso y elevado cargo que les confirieron las Juntas generales antes que ver menoscabadas en sus manos en lo más preciado las instituciones que habían jurado guardar y defender ${ }^{79}$. Sancionada la Ley de julio, la postura de los representantes forales de Vizcaya se mantuvo estable, lo que se tradujo en su decidido rechazo a la Ley y su negativa a cualquier gesto de negociación que pudiera entenderse como una aceptación implícita. Su idea era la de renunciar a sus cargos y dejar en suspenso el régimen foral antes que aceptar que éste pudiera verse limitado. El mantenimiento de tales posturas originó que asomara alguna fisura con las otras dos provincias, más dúctiles o menos intransigentes si se prefiere. Así en una reunión que celebraron las Diputaciones de las tres provincias unos días antes de la Ley de julio se manifestaron diferencias de criterio, entendiendo los representantes vizcaínos que una vez aprobada dicha ley éstas instituciones carecían de base legal para continuar existiendo y que, por tanto, los diputados forales debían dimitir, si bien y para no aparecer desunidas, finalmente se plegaron a la opinión de las otras dos provincias, contrarias a este criterio ${ }^{80}$.

\footnotetext{
78 Carta de Roca-Verde a Lasala, 7 de mayo de 1876, en AGG, FDM, 62.

79 Sesión de 4 de mayo de 1876. ADFB, J-00263.

${ }^{80}$ Reunión en Vitoria, el 15 de julio de 1876, en AGIRREAZKuENAGA, Joseba (ed.): La articulación politica-institucional de Vasconia: Actas de las Conferencias firmadas por los representantes de Álava, Bizkaia, Gipuzkoa y eventualmente de Navarra (1775-1936), vol. I, Bilbao, 1995, p. 784.
} 
No obstante, no hubo tiempo para que se sustanciaran posibles divergencias pues el triunfo de las posiciones intransigentes en las Juntas Generales de las tres provincias, celebradas en setiembre de 1876, permitió reforzar la unidad interna y fijar como criterio compartido que ante la eventualidad de que la «administración foral» termine, «ha de entenderse que queda en suspenso por causas superiores e invencibles y no concluida definitivamente; pues el País ha de conservar en todos tiempos incólumes sus derechos...» ${ }^{81}$. Parecía que la línea de rechazo frontal a las intenciones del Gobierno se había hecho fuerte en todo el ámbito vasco y en esa misma dirección las Diputaciones acordaron tajantes que si el gobierno persistía en poner condiciones para la convocatoria de nuevas Juntas, dimitirían de sus puestos y suspenderían el régimen foral ${ }^{82}$. Se mantuvieron iniciativas conjuntas que reafirmaban esa idea del frente de rechazo, y así en diciembre comisionados vascos se reunían con Cánovas para presentarle una exposición pidiéndole la revocación de la Ley ${ }^{83}$, o bien, dos meses más tarde, rechazaban las bases ya comentadas de arreglo presentadas por Quesada, bastante beneficiosas para el País Vasco. Resultaba significativa la respuesta dada por las Diputaciones a esta última iniciativa, redactada por la cabeza de la intransigencia, Fidel de Sagarmínaga, exponiendo con claridad que «las Diputaciones se hallan en la imposibilidad de tratar bajo la base de la aceptación de la ley de 21 de Julio" y que sólo prescindiendo de esta base estaban dispuestos a entrar en negociaciones. Era una situación de punto muerto, que abocaba al ejecutivo a adoptar medidas contundentes en orden a la aplicación de la Ley de julio.

Lo cierto es que a comienzos de 1877 la situación se tornaba aún más difícil, con un frontal enfrentamiento entre el Gobierno y las instituciones vascas; cerradas a una transacción con el ejecutivo mientras éste no desechara la Ley de julio. Lo crítico del momento favoreció la emergencia de las posiciones transigentes, que salieron de su ostracismo y promovieron un giro en la orientación de Álava y Guipúzcoa hacia posturas más flexibles y abiertas a la negociación, tomando un rumbo propio y dejando sola — si no había otro remedio- a Vizcaya. Se rompía de esta forma uno de los pilares de la estrategia vasca, la unidad de acción, requisito imprescindible para que sus iniciativas pudieran tener alguna operatividad, a la vez que Cánovas veía su camino allanado. Igualmente, lo delicado de la situación favoreció que aparecieran divergencias o descon-

81 Reunión de las Diputaciones Forales, 8 de diciembre de 1876, en AgIRREAZKUENAGA, J. (ed.): La articulación...., cit., vol. I. , p. 806.

82 El Gobierno pedía para su convocatoria la aceptación de la Ley de julio, aunque luego se pactó con guipuzcoanos y alaveses una fórmula más ambigua. Se decía en ese acuerdo de las Diputaciones que caso de que el Gobierno quisiera poner alguna condición a la convocatoria de las Juntas «ha llegado el caso de la resignación de sus puestos y de la suspensión del régimen foral en el País vascongado quedando íntegros e incólumes sus derechos». Reunión de las Diputaciones, 1 de febrero de 1877, en AGIRREAZKUENAGA, J. (ed.): op.cit., vol. I, p. 812.

83 Sobre esta reunión celebrada el 16 de diciembre de 1876: ADFB, J-00263; y LASALA, F.: Última etapa..., cit., vol. II, p. 140.

Hispania, LXV/2, núm. 220 (2005) 601-642 
fianzas en las filas de la intransigencia. De este modo, el Diputado General de Álava desautorizó al conde de Llobregat, un intransigente tibio al fin y a la postre, por las gestiones que estaba llevando cerca de Cánovas, añadiendo que no tenía ningún encargo colectivo ${ }^{84}$. Asimismo la correspondencia mantenida entre las Diputaciones ${ }^{85}$ reflejaba recelos y desavenencias entre los dirigentes vizcaínos y los de las otras dos provincias, que se concretaban básicamente en que los primeros consideraban que no existían posibilidades de llegar a acuerdos con el ejecutivo, en tanto que los segundos no cerraban totalmente esa eventualidad. En este contexto, las bases de arreglo que presentó Quesada, en febrero de 1877, fueron un impulso importante para las tesis transigentes que se encontraron con una propuesta que creaba cuando menos expectativas de arreglo. En Álava y Guipúzcoa se vivió una intensa agitación en favor de estas posiciones, que fue comandada por localidades de la provincia en este segundo caso, teniendo que aceptar las respectivas Diputaciones la convocatoria ${ }^{86}$ de unas nuevas Juntas Generales (Juntas extraordinarias, denominadas «Particulares» en Guipúzcoa), que se van a desarrollar bajo el signo de la transigencia. Parecía que se abrían nuevas posibilidades y que se podría encontrar una vía de acuerdo. Pronto, sin embargo, quedó frustrado este nuevo horizonte.

El giro operado en Álava y Guipúzcoa fue vivido por las autoridades provinciales vizcaínas como un abandono, una suerte de traición, entendiendo que al convocar las Juntas ambas provincias estaban dando su "asentimiento» a la Ley de julio ${ }^{87}$ y venía a ser «el triunfo de la política» de Cánovas ${ }^{88}$. No les faltaba razón a los vizcaínos cuando denunciaban su aislamiento, pues no en vano el principal punto de discordia en las Juntas de Álava fue el grado de vinculación que se debía mantener con las otras provincias. Triunfó, como se ha dicho, la posición transigente, lo que supuso que se optara por una fórmula de relación laxa, que no ataba la suerte de Álava a Vizcaya y le dejaba, en definitiva, con las manos libres a la hora de determinar cuál había de ser su estrategia, sin verse condicionada por la línea de dureza de su poderosa vecina ${ }^{89}$.

${ }_{84}$ Carta de Martínez de Aragón, 10 enero de 1877, ADFB, J-00264.

${ }^{85}$ Véase ADFB, J-00264. Mercedes Vázquez de Prada, en el libro ya citado, recoge alguna de esa interesante correspondencia.

${ }^{86}$ La fórmula de convocatoria de la Junta fue muy importante pues prejuzgaba su orientación, y en ella se indicaba que tal hecho se producía: "para tratar y resolver en la forma más conveniente los asuntos conexionados con las disposiciones de la ley de 21 de Julio de 1876».

87 En la reunión de la Comisión permanente de Fueros de Vizcaya, el consultor del Señorío, Lecanda, se levantó para decir «que Vizcaya se veía combatida por todos y abandonada hasta cierto punto por las provincias hermanas, que habían concluido por dar su asentamiento a la ley de julio último.» Acta de la Comisión permanente de Fueros, ADFB, J-00263, 27 de marzo de 1877.

88 SAGARMínAGA, F.: «Controversias forales», en Memorias históricas.., cit., p. 244.

${ }^{89}$ La propuesta victoriosa decía que «procurando por todos los medios posibles ir de acuerdo con las dos Provincias hermanas Guipúzcoa y Vizcaya», en tanto que la derrotada proponía sustituir este párrafo por el más taxativo de ir «de acuerdo» con las dos Provincias... Es decir, en esta segunda acep- 
Lo cierto es que la intransigencia quedaba reducida a Vizcaya, pero no sin discrepancias y problemas. En la sesión del Regimiento General de Vizcaya que abordó en marzo la trayectoria que debía seguir el Señorío tras la convocatoria de Juntas adoptada por Álava y Guipúzcoa, se manifestó una profunda división entre sus componentes, ganando por sólo tres votos (16 a 13) los partidarios de no reunir a las Juntas sobre los que sí lo eran. Triunfaba, pues, la línea intransigente, defensora de anteponer el "principio», pero con un evidente desgaste de lo que daba buena cuenta la fragmentación del voto y que los dos diputados generales se alinearan en bandos opuestos ${ }^{90}$. Tras esa decisión y después de una nueva conminación de Quesada por la cual si no convocaban Juntas aplicaría con severidad la Ley de julio, la Diputación decidió renunciar y cesar en sus funciones, siendo sustituida por una nueva, que fue la que convocó Juntas Generales que, ante el cariz intransigente que tomaban, fueron disueltas por el gobernador de la provincia. Se había llevado a la práctica la línea de no cesión ante el ejecutivo preconizada por Sagarmínaga, con una política que parecía suicida, pero que respondía a un sentir muy extendido en las provincias vascas, renuentes a perder lo que para ellas eran costumbres seculares en tanto que para Cánovas resultaban privilegios. Antes que desarrollar una línea posibilista, se impuso en Vizcaya la idea de que lo importante era «salvar cuando menos la bandera, esto es, la idea del derecho (...) y cerrar la puerta a todo acomodamiento infidente, que diese por resultado el abandono del derecho foral» ${ }^{11}$. Era una filosofía compartida por la intransigencia en general, con un punto de partida fantasioso en la creencia de que se vivía una crisis pasajera más, y que, por tanto, era conveniente dejar en «suspenso» el régimen foral, para que posteriormente pudiera restablecerse incólume. Lo expondrá con claridad a los pocos meses el alavés Martínez de Aragón en su última alocución como Diputado General:

«Y que al entender que por la situación de fuerza que por la ley abolitoria de fueros se encuentra la provincia debe dejarse en suspenso el régimen foral para volver a ejercitarse íntegro, absoluto y como a su antiguo estado y derecho debe corresponderle. No cree este país pierde nada ni ninguno de sus imprescindibles derechos, sino que por el contrario el acto de suspensión del régimen foral es para conservarlo incólume, entero y virgen de abdicación ni aún de aparente consentimiento de derogación»92.

Entretanto, en Álava y Guipúzcoa fue la hora de la transigencia. Una estrategia que albergaba también diferentes talantes ${ }^{93}$, pero a la que le unía su re-

ción no había que "procurar» sino que había que ir con las otras dos. ATHA, Actas de las Juntas Generales de Álava, febrero de 1877, pp. 23 y ss. Consignar que Guipúzcoa optó por la mismạ fórmula.

90 Una descripción interesante y de primera mano sobre Sagarmínaga y Bruno L. de la Calle, en LASALA, F.: Última etapa..., cit., tomo II, pp. 174 y ss.

91 SAgarmínaga, F.: «Controversias forales», en Memorias bistóricas..., cit., pp. 234-235.

92 Sesión de la Junta Particular de Álava, 7 de junio de 1877, ATHA, 726/3, p. 140.

93 Dentro del ámbito guipuzcoano podemos distinguir la figura de F. de Lasala, el más conspicuo representante de esta línea, de la del Marqués de Roca-Verde, más exigente en sus peticiones al Gobierno. 
chazo al radicalismo fuerista, y una percepción más ajustada del momento que vivían, que pasaba considerar que el arreglo foral resultaba inevitable ${ }^{94}$. De esta manera, su objetivo pasaba por negociar con el gobierno una aplicación flexible de la ley de julio en la idea de no ser integrados en el régimen común y que el País Vasco continuara con un sistema peculiar ${ }^{95}$. La cuestión básica para ellos era el tema de la hacienda ${ }^{96}$, de la fiscalidad, en lo que coincidían con los intransigentes, pero al que daban un tratamiento diferente. Si para estos últimos dicha materia se subordinaba a la defensa del «principio», para los transigentes, en cambio, era un punto vital al que deseaban encontrar una solución que pasaba por mantener su especificidad dentro del Estado, estableciendo un vínculo especial con la Hacienda central que le garantizase el pago de una contribución reducida y mantener una importante autonomía fiscal. Que la conciliación de intereses no iba a resultar fácil lo había anunciado en mayo de 1876 el propio marqués de Roca-Verde cuando señalaba:

«en la cuestión metálica no aceptaría, por mí, nada que no saliera de una contribución única fija anual, que no sufra alteración y que no sea de mucha cuantía. En lo de la quinta no tendría inconveniente en ser muy elástico»97.

Era un punto de partida que permitía prever que tampoco con los transigentes el arreglo iba a ser sencillo.

En este sentido, las resoluciones adoptadas en las Juntas de febrero-marzo de Álava y Guipúzcoa, así como los ulteriores acontecimientos, reflejaron las ambigüedades y vacilaciones en las que se desenvolvió este sector. Los compromisos adoptados en ambas Juntas fueron idénticos y en ellos se sentaban unas bases de negociación que en lo sustancial venían a recoger la propuesta formulada en febrero por Quesada: mantenimiento del organismo foral, contribución única en sustitución de otros conceptos tributarios y negociación en el contingente militar. A estas alturas de la crisis, era muy importante para los transigentes conceder «estabilidad» y «fijeza» a los acuerdos a que se llegasen, saliendo de la provisionalidad e indeterminación en la que se habían movido las provincias vascas hasta ese momento. El contexto político había cambiado y ahora los transigentes vascos consideraban que esas bases eran lo suficientemente satisfactorias como para ser recogidas en un texto legal, que les pusiera a salvo de futuros males mayores. Pero, además, a los negociadores que tratasen con el ejecutivo se les ponía la condición que en el «acto legislativo» en el que

\footnotetext{
94 Una buena síntesis de las posturas transigentes e intransigentes, en LASALA, F.: Última etapa..., cit., vol. II, pp. 247 y ss. FDM, 62.

95 Véase a este respecto la carta de J.M. Brunet a F. Lasala, el 20 de marzo de 1876, en AGG,

96 Véanse las cartas del Marqués de Roca-Verde a Lasala, 1 y 7 de abril de 1876, en AGG, FDM, 62.

97 Carta de Roca-Verde a Lasala, 10 de mayo de 1876, en AGG, FDM, 62.
} 
se recogiesen los acuerdos a que se pudieran llegar, «se exprese explícitamente un derecho anterior a la ley (de julio), eslabonando esta, en cuanto sea posible, con lo dispuesto en la de 25 de octubre de 1839». Vericueto jurídico, fórmula un tanto confusa, con la que se buscaría sortear la ley de julio del 76 y establecer una legitimidad anterior, basada en ley del 39, que ofrecía, al entender de los vascos, un mayor margen de maniobra para sus intereses. Otra cuestión que a la altura que estamos se va a revelar clave fue que en esas bases de arreglo, la parte vasca señaló que esa cantidad anual a pagar debería ser «única y alzada», lo que al poco tiempo y en el transcurso de las negociaciones se traducirá en la práctica en «fija e invariable», como se verá.

Las reacciones no se hicieron esperar. El Diputado General de Álava, Martínez de Aragón, disconforme con el nuevo rumbo, presentó la dimisión, que sin embargo no fue aceptada. Por su parte, en el poder ejecutivo las posiciones variaban desde la satisfacción de Quesada hasta la cautela de Cánovas, que mantuvo criterios oscilantes, pero dentro de una tónica de prudencia. Si en principio calificaba el resultado de la Junta de «excelente», días después indicaba que era satisfactorio si las condiciones no eran «absolutas», a la par que manifestaba sus recelos ante la nueva situación entendiendo que el acuerdo de la Junta, tal como estaba redactado, iba a resultar ineficaz y «a embrollar la cuestión» ${ }^{98}$.

Una cuestión capital era quienes iban a asumir en la parte vasca la función negociadora con el gobierno habida cuenta que la Diputación guipuzcoana continuaba presidida por un intransigente (Juan B. de Acilona), que no era precisamente favorable a entrar en transacciones con el ejecutivo. No es de extrañar, por tanto, que en la Junta de Guipúzcoa esta cuestión fuera el punto que suscitó una mayor discrepancia, ganando las posiciones transigentes por una ajustada mayoría; en consecuencia, "para la ejecución del acuerdo" de las Juntas se constituía, «asociada» a la Diputación, una comisión dotada de voto resolutivo. Sin embargo, llegado el momento de nombrar a las personas que debían tratar con el gobierno sobre las bases acordadas en la Junta, su puso en evidencia la debilidad de la transigencia guipuzcoana, su tibieza y escasa consistencia. De los cinco designados, tres de ellos declinaron el ofrecimiento ${ }^{99}$, precisamente los de mayor prestigio, quedando prácticamente inutilizada esta comisión y en manos de la diputación intransigente los contactos con el gobierno. Los transigentes guipuzcoanos permitieron, pues, que acudieran a Madrid dos comisionados de la otra fracción, que llevaron una propuesta que en nada se asemejaba a lo acordado en la Junta de marzo y que hacía imposible todo acuerdo ${ }^{100}$.

En Álava la situación era también contradictoria, y el predominio «oficial» de las posiciones más favorables a la negociación, se contrarrestaba con el peso

98 AGA, PG, 104, 108 y 109. CAJAL, A.: «Pensamiento del general Quesada ...», cit.

99 Ellos fueron Fermín Lasala, Aguirre-Miramón y el conde de Llobregat.

${ }^{100}$ Acuden el Diputado General Acilona y su adjunto Casimiro Guerrico para tratar exclusivamente el tema de las quintas por ese año y con el objetivo de que no se produjera el reemplazo (AGA, PG, 104, 105 y 108).

Hispania, LXV/2, núm. 220 (2005) 601-642 
que las posturas intransigentes tenían entre las personalidades de mayor calado de la provincia, como eran, por ejemplo, el Diputado General, Martínez de Aragón, que continuaba en su cargo, o B. Mateo de Moraza y Pedro de Egaña, que rechazaron además integrarse en la comisión negociadora ${ }^{101}$. Los que finalmente formaron parte de esta comisión, a pesar de que fueron calificados de manera opuesta por el gobierno, sintonizaban con Martínez de Aragón, con lo que venía a darse la paradoja de que en las dos provincias tocaba a los afines a la intransigencia aplicar la política de la transigencia. Una manera evidente de hacer que ésta fuera inviable. No obstante, siguiendo lo convenido en las Juntas, ambas provincias prepararon en mayo unas bases de negociación con el Gobierno ${ }^{102}$, que no hacían sino desarrollar los puntos acordados en aquella reunión y con estos presupuestos se va a producir una nueva reunión con Cánovas.

Lo cierto es que había transcurrido casi un año desde la Ley de julio y las instituciones vascas continuaban con su resistencia pasiva a la Ley, o bien trataban de que su aterrizaje resultara lo más liviano y favorable a los intereses del País. Existía un clima de incredulidad respecto a que el Gobierno fuera a adoptar una política severa y se continuaba en la idea de que, al igual que en anteriores ocasiones, el tiempo corría a su favor. Se persistía en el error de cálculo y determinados comentarios, desde luego interesados, alimentaban' a estas alturas unas expectativas que distaban de ser reales ${ }^{103}$. Que las cosas esta vez eran distintas lo puso en evidencia Cánovas cuando a principios del mes de mayo resolvió asimilar a Vizcaya al régimen general, lo que pretendía ser todo un aviso a las otras dos provincias sobre sus intenciones y cómo debían encarar las negociaciones.

Sentadas estas bases, se produce en este mismo mes de mayo la reunión de los comisionados vascos con Cánovas en la que se escenificaron las diferencias. Aunque ambas partes hicieron explícito al comienzo su disposición a llegar a un arreglo, enseguida se manifestó que había un punto que hacía imposible tal acuerdo. En efecto, cuando se abordó el tema central de la entrevista, la cuestión contributiva, volvió a verse que había dos puntos de vista muy dispares. Los comisionados alaveses y guipuzcoanos expresaron que estaban dispuestos a ofrecer una cantidad, pero que ésta debía ser «fija e invariable», es decir, pagar una cifra inmutable a lo largo del tiempo. Cánovas repuso que «esto no era posible", oponiendo el criterio de que

101 VÁZQUEZ DE PRADA, M.: «Del régimen foral al concertado...», cit., p. 95. Sobre Álava véase también, GONZÁLEZ DE ZÁRATE, Víctor: Del pacto foral al pacto autonómico: provincia de Álava, 18761906, Vitoria, 1997.

102 Pueden consultarse en el ATHA, D.H. 259/4, y están recogidas por VÁzQUEZ DE PradA, M.: Negociaciones..., cit., pp. 576-583.

${ }^{103}$ Los Diputados forales de Guipúzcoa Acilona y Guerrico «aseguran que tienen noticias muy favorables de Madrid en dicho sentido", en decir, acerca de las posibilidades de llegar a un arreglo que no reconozca la Ley. Telegrama del gobernador civil, 8 de abril de 1877, AGA, PG, 108.

Hispania, LXV/2, núm. 220 (2005) 601-642 
«la ley obligaba a los Vascongados cual a todos los españoles a contribuir en proporción de su riqueza; que establecía la proporcionalidad para todos los sacrificios, y sentado este principio no era posible fijar una cantidad determinada que no hubiera de variar pues la cifra siempre dependería del tipo de la contribución que las Cortes señalaren, y además la fijeza que pretendíamos no era compatible con la proporcionalidad que nos obligaba en todos los servicios» 104

Los vascos venían a plantear el modelo de relación económica que había existido con Navarra, cuando precisamente éste acababa de cambiar tras las negociaciones entre representantes de esta provincia y del Gobierno, a resultas de las cuales se incrementó el cupo que aportaba esta provincia, rompiéndose la idea sostenida por los navarros de que tal cupo era inamovible ${ }^{105}$. En cualquier caso, a la exposición de Cánovas, los comisionados vascos - recuérdese que eran afines a la intransigencia-, no hicieron una contraoferta e indicaron que no podían variar su propuesta pues era un mandato de las Juntas Generales ${ }^{106}$. El planteamiento de Cánovas acerca de la proporcionalidad resultaba congruente con su trayectoria, pues lo había formulado ya en las reuniones iniciales de mayo de 1876 y había quedado refrendado en el texto de la Ley de julio de este año. No era, por tanto, resultado de un endurecimiento de la política de Cánovas y lo sorprendente no es que lo suscitara, sino más bien la falta de respuestas de los representantes vascos. Se llegaba de este modo a un punto muerto en las negociaciones, poniéndose en evidencia las sustanciales discrepancias que se daban también con las propuestas de los transigentes.

Al final de esta conferencia se acordó continuar los contactos a través de Quesada, pero era claro que la situación se tornaba cada vez más favorable para Cánovas. Se había producido la división entre las provincias, la intransigencia había perdido posiciones, y la Ley de julio, en lo que hacía referencia al reemplazo militar, se iba ejecutando no sin trabas. Los acontecimientos venían a reafirmar la desconfianza que ahora ya mostraba Cánovas también con los transigentes, de los que «recelaba» por su forma equívoca de actuar y a los que venía a imputar de falta de «decisión y sinceridad»107. En realidad lo que existían eran dos puntos de vista muy distantes y ninguna voluntad de ambas partes por alterar sus posiciones.

Los hechos se iban precipitando a medida que se iba produciendo un creciente debilitamiento de las posiciones vascas. Fue en Álava donde esta situación se manifestó de modo más palpable. En junio de 1877, en el curso de una Junta Particular, se planteó un debate similar al referido para Vizcaya acerca

${ }^{104}$ Continuaba Cánovas diciendo: «Que aunque se estableciera la proporcionalidad no la exigiría él desde luego sino que podría indicarse otro temperamento como el de una escala gradual».

10s Sobre este punto véase, sobre todo, MARTínEZ BeloQUI, Ma ${ }^{\mathrm{a}}$. Sagrario: Navarra, el Estado y la Ley de Modificación de Fueros de 1841, Pamplona, 1999, pp. 237 y ss.

106 Actas de la conferencia celebrada el 19 de mayo de 1877, ATHA, D.H. 259/4.

1074 de marzo de 1877, AGA, PG, 108. 
de dejar en suspenso o no el régimen foral, triunfando el dictamen de los transigentes, contrarios a tal medida, aunque la endeblez de su posición se reflejaba en el sorprendente reconocimiento de que «a pesar de hallarse conformes con las observaciones de los que quieren la suspensión», votaban contra ella. En la explicación de su propuesta, alegaban cuestiones de forma, pero sobre todo consideraban que su «deber es alejar todo lo posible el que sobre esta provincia pesen toda clase de tributos». Había, pues, que exprimir toda posibilidad para lograr un buen trato fiscal. El todavía Diputado General, Martínez de Aragón, hizo una intervención contundente en favor de la suspensión del régimen foral, acabando por señalar que él en cualquier caso renunciaba a su cargo, o dicho más textualmente, se retiraba a su casa ${ }^{108}$. Su dimisión irrevocable permitió a los transigentes ocupar también la cabeza de la Diputación en la persona de J. Bravo, pero en un marco de extremada debilidad, de lo que daba buena cuenta el escaso peso en la provincia del recién elegido, que contrastaba con la relevancia social de sus oponentes, varios de los cuales pasaron a ausentarse de las instituciones forales.

El dominio de la transigencia en esta provincia quedó confirmado en las Juntas Generales, celebradas en julio, en la que se liberaba de cualquier constricción a los negociadores, al indicar que debían tratar «sin limitación alguna con el gobierno» todo lo relacionado con la ley de julio ${ }^{109}$. De poco iba a servir esta libertad de acción que se concedía a los representantes alaveses. En setiembre se produjeron nuevas reuniones entre Cánovas y comisionados alaveses y guipuzcoanos, que no hicieron más que constatar lo encontrado de las posiciones, reiterándose argumentos ya conocidos, sin que las posturas variasen. Así, frente a la reclamación de Cánovas de una cantidad proporcional a la riqueza, contribución que en cualquier caso «el Gobierno no apresuraría su realización», el Diputado General de Alava, el transigente Bravo, contestó que no podía entrar en esa cuestión y que sólo las Juntas Generales eran competentes para hacerlo. A instancia de Quesada, presente en la reunión, se acordó para el caso de Álava aplazar cualquier resolución a la celebración de unas nuevas Juntas Generales en noviembre ${ }^{110}$. Cánovas no esperó. Se sentía ya en una posición de fuerza, y estaba, además, harto de las dilaciones de las autoridades forales. No confiaba en las de Guipúzcoa, de las que se planteó su sustitución, pero es que tampoco atisbaba un posible acuerdo con la transigencia. Ésta, debilitada ante la falta de resultados y con una presión interior muy fuerte, no se atrevía a aceptar las bases propuestas por Cánovas y aparecer públicamente como los

${ }^{108}$ Actas de la Junta Particular de 7 y 8 de junio de 1877, ATHA, 726/3, pp. 126 y ss. Agradecemos las utilísimas indicaciones para esta provincia del profesor Orruño.

${ }_{109}$ Extractos de las Juntas Generales celebradas en Vitoria los días 6 al 9 de julio de 1877, ATHA, 205/ 1

110 Acta de la Junta Particular de Álava, 8 de setiembre de 1877, ATHA, D.H. $259 / 4$. 
introductores de la Ley de julio en el País Vasco. Se hallaba en un callejón sin salida, paralizada y sin respuestas ${ }^{111}$.

Cánovas ya no dudó, y en los meses de noviembre-diciembre primero introdujo por un R.D., un tipo de contribución general en el País Vasco. La reacción en las instituciones forales del País fue la vuelta a las posiciones iniciales, al rechazo a la Ley de julio y a expresar terminantemente que no podían «contribuir ni cooperar directa ni indirectamente a su cumplimiento» ${ }^{112}$, como expusieron las últimas Juntas Generales celebradas en el País Vasco, las de Álava en noviembre de 1877. Puestas así las cosas, Cánovas cortó por lo sano, disolvió las Juntas y Diputación Foral alavesa, y a continuación la guipuzcoana, para designar después unas nuevas diputaciones ya de carácter provincial. Será con ellas, como ya se ha dicho, con las que Cánovas negocie la excepcionalidad administrativa del País Vasco a través del Concierto Económico. Será también el momento de la otra transigencia, de aquellos sectores del País que asumiendo que el nuevo marco era inevitable, negocien con Cánovas el nuevo status y las nuevas condiciones contributivas. Se llegará así a un punto en el que los vascos tendrán que ceder en la idea de la inalterabilidad del cupo, pero también Cánovas entenderá de una manera muy flexible lo de la proporcionalidad, llegándose a acuerdos económicos que en términos comparativos con el resto de España eran muy favorables para estas provincias, tal como lo reconoció el propio Presidente del Gobierno.

\section{CONCLUSIONES}

Se llegó así a un nuevo régimen en el País Vasco después de un año y medio de tensiones y negociaciones entre el ejecutivo y los representantes del País. Se atravesaron diferentes fases pero, como hemos tratado de demostrar, los puntos de partida eran demasiado distantes. Con la transigencia se abrieron nuevas expectativas, pero la flexibilidad que se presuponía a las dos partes, encontró pronto el obstáculo insalvable de la proporcionalidad. Fueron en este sentido unas negociaciones imposibles, inviables, esperando las diferentes partes que la otra cediese. Cánovas que se aceptasen sus ofertas acerca de una aplicación favorable de la Ley, los transigentes que se reconociera su buena disposición y se admitiera una cantidad fija e invariable, y los intransigentes - al margen de las transacciones - que se dilataran las negociaciones hasta que llegaran mejores tiempos. No hubo en aquel contexto unas posibilidades reales

\footnotetext{
111 En una Junta Particular de Álava celebrada en noviembre, la subcomisión formada para gestionar la cuestión económica reconoce que se halla en una «situación crítica y embarazosa», y se asume por la Junta que no se ha avanzado, pero tampoco se realiza ninguna nueva propuesta. La reunión es del 14, un día después del R.D. que mencionamos a continuación, pero no se hace referencia a él. ATHA, 146/12.

112 Del texto que las comisiones presentan a las Juntas Generales de Álava, 20 de noviembre de 1877, ATHA, 57/3.
}

Hispania, LXV/2, núm. 220 (2005) 601-642 
de acuerdo, y sólo cuando se produjo la circunstancia traumática de la supresión de los organismos forales, la que podemos considerar como la tercera vía que existía en el País que no era sino una derivación de la transigencia, asumió la nueva situación para entrar a negociar con Cánovas el cupo que habían de pagar las provincias vascas.

En cualquier caso, las posibilidades para un acuerdo no eran desde luego fáciles porque las medidas que planteaba Cánovas fueron sentidas en el País Vasco como una agresión a un sistema secular. Aunque la conclusión de la crisis pudiera ser esperada, produjo en cualquier caso un profundo y negativo efecto $^{113}$. La vigencia del régimen foral y lo que éste comportaba había favorecido la germinación no sólo de voces ancestrales, sino también había acostumbrado a los habitantes del País al disfrute de unas ventajas a las que no estaban dispuestos a renunciar. Es en este contexto donde hay que enclavar la fuerza de la intransigencia en el País Vasco y el hecho de que veamos alineados tras esta postura a personalidades de talante moderado, gentes conservadoras, que, sin embargo, consideraban inaceptable la Ley de julio.

Por contra, todo aquello que se entendiera como un asentimiento de dicha Ley parecía suscitar el rechazo de buena parte del País, y es así también como podemos entender las dificultades referidas de los transigentes. Su estrategia tenía que desenvolverse en un ambiente de desconfianza, tal como puede deducirse del lamento del Diputado General transigente J. Bravo, que percibía que en la ejecución de esa política en Álava «era tal la presión pública por que estaba atravesando la representación de la provincia, efecto de las circunstancias desagradables que a ésta se le echaban encima, que su prestigio iba decreciendo de una manera considerable...» ${ }^{114}$. Las modificaciones adoptadas en la Ley de julio afectaban a todas las capas de la sociedad vasca; podrían concernir a los más pudientes a través de las nuevas relaciones contributivas, pero de momento era a los sectores populares a los que más perjudicaban como consecuencia del alistamiento militar. Por tanto, era comprensible que no estuviera bien visto aceptar el nuevo statu quo y que aparecer aprobando medidas consideradas contrarias al régimen secular, por muy racionales que resultaran, fuera reputado como «ese valor cívico es una virtud heroica que a nadie puede exigirse» ${ }^{115}$. Pero quizá el ejemplo más contundente de ese ambiente hostil resultó el ostracismo que sufrió uno de los grandes caciques de Guipúzcoa, F. de Lasala, que después de salir elegido diputado al Congreso casi ininterrumpidamente desde 1857 por el distrito de San Sebastián ${ }^{116}$, va a poner, según él mismo se-

113 Véase el testimonio posterior de un fuerista templado como OruETA, José de: Memorias de un bilbaíno, Bilbao, reed. 1993, pp. 91-92.

114 Acta de la Junta Particular de Álava, 8 de setiembre de 1877, ATHA, D.H. $259 / 4$.

115 Carta del conde de Llobregat a J. B. Acilona, 14 de enero de 1877, ADFB, J-00264.

116 Vino a heredar el distrito de su padre, electo entre 1846 y 1853, año en el que falleció. En las elecciones de 1869, ante la marea carlista en el País Vasco, se presentó por Burgos y en las de 1873, con la República, no se presentó, pero volvió a ser elegido en enero de 1876

Hispania, LXV/2, núm. 220 (2005) 601-642 
ñalaba, «término a mi carrera política» en esta provincia, como consecuencia de aparecer como el adalid de la transigencia en el País Vasco ${ }^{117}$. Continuó ocupando importantes cargos en el Estado, pero su público posicionamiento en favor del entendimiento con el Gobierno fue un lastre que mermó sustancialmente su capacidad de influencia en Guipúzcoa.

A pesar de las tentativas de Cánovas de conseguir algún grado de cooperación con el País, lo cierto es que el clima que pareció predominar en las provincias vascas era de fustración y descontento con respecto al tratamiento que estaban recibiendo. Recuérdese el argumento que veíamos que empleaba Llobregat para explicar la radicalización que se vivió en el País y las reacciones que en este sentido se suscitaron en las propias filas de los liberales vascos ante la campaña contra el Fuero desatada en el resto de España. Vencido el carlismo, muchos liberales vascos debieron vivir con profundo disgusto la postura de Cánovas para con estas provincias, considerando que no merecían esa política e incluso que se les trataba como a territorios "conquistados»118. En este sentido, que se mantuviera hasta noviembre de 1879 la suspensión de las garantías constitucionales ${ }^{119}$, cuando en el resto del Estado se levantaron en enero de 1877, ayudaba a que se utilizase esa imagen, desde luego exagerada, de "conquistados", y que el ejército que derrotó a los carlistas pasara a ser comúnmente denominado «ejército de ocupación» ${ }^{120}$. Algunos de los textos contemporáneos emanados desde el País reflejan esa sensación de ser mirados con beligerancia, de ser agredidos desde fuera, cultivando un sentimiento tan rentable para promover cohesiones internas y posturas radicales como el del victimismo. No era, pues, un momento propicio para que las posturas transaccionistas pudieran expandirse, y sí por contra para formular agravios y reivindicar lo que se entendían que eran antiguos derechos.

En este sentido, varios de los discursos de los parlamentarios vascos o algún texto presentado por las Diputaciones debido a Trueba, fueron una elocuente expresión del sólido entramado teórico que se había forjado en el País Vasco destinado a defender en primera instancia su régimen foral, y en cualquier caso su excepcionalidad en el sistema común. Argumentos tipo de que «las Provincias Vascongadas están en posesión de sus fueros, que estos fueros se han mantenido por los vascongados, no como privilegios, sino como derechos perfectos, como derechos originarios", así como que los Fueros son «símbolo de libertad y

117 Véase cómo describe este arrinconamiento en LASALA, F.: Última etapa..., cit., vol. II, pp. 135 y ss.

118 Carta del Diputado General de Álava, R. Ortés de Velasco, 13 de mayo de 1876, ADFB, J00264 .

119 Medida a la que coadyuvaron, entre otras cosas, los datos que siguieron llegando al general Quesada y al Gobierno sobre proyectos insurreccionales carlistas y republicanos (AGA, PG, 108).

${ }^{120}$ Hay que ser en cualquier caso cuidadoso a la hora de interpretar la significación que se le concedía en aquel momento a determinados términos como pudiera ser éste, que es asimismo utilizado por Cánovas (DSC, 11-12-1878, pp. 4024-4025), suponemos que de un modo no peyorativo sino sólo descriptivo.

Hispania, LXV/2, núm. 220 (2005) 601-642 
de orden, y que por tantos siglos han hecho la felicidad del país vascongado, que también es parte de España» ${ }^{121}$, se repitieron hasta la saciedad por parte de los representantes vascos. No es el caso de que recojamos los argumentos teóricos empleados en esta coyuntura, que se sostenían sobre una base historicista y mitificadora, pero sí cuando menos que reflejemos el alto grado de cohesión que reflejaban tales exposiciones o proclamas, que permiten entrever que debían gozar de un alto grado de calado popular. Existía, pues, un clima de exaltación que incitaba a que gentes que en el futuro veremos como contrarias al radicalismo fuerista intransigente, se alineen ahora tras esta bandera: era el caso del adolescente y melancólico Unamuno, o, en términos más locales de F. Gascue $^{122}$.

El desenlace de esta crisis pareció suponer un triunfo de Cánovas por un lado y de la intransigencia por otro, en tanto que las posturas más flexibles y favorables a explorar vías de entendimiento con el ejecutivo resultaron laminadas. Cánovas consiguió aplicar el principio de «la unidad constitucional», en tanto que los intransigentes veían cómo las autoridades forales no mancillaban el régimen foral, que así quedaba, desde su perspectiva, incólume y presto para ser restaurado íntegro cuando el viento político soplara favorable. Sin embargo, al poco de discurrir el tiempo, las cosas se empezaron a ver de otra manera. En lo que atañe a Cánovas, apuntar que la Ley de julio quedó en el imaginario del País Vasco como una fecha infausta, momento en el que se produjo la abolición de su régimen secular, de un sistema que desde la visión mitológica dominante era «el baluarte de nuestra felicidad», $y$, en este sentido, punto de partida reiterado de reivindicaciones sobre un nuevo status para el País. Es cierto que había mucho de retórico y formal en esas reclamaciones, pero de cualquier forma la Ley de julio se tomaba como referente para expresar un cierto grado de descontento con respecto a la relación entre el País Vasco y el Estado.

En cuanto a la intransigencia, su fracaso resultó casi inmediato. Su visión estratégica se reveló como profundamente equivocada y los cambios de gobierno no supusieron la vuelta del régimen foral, sino en todo caso profundizaron en la vía abierta por Cánovas. Trató la intransigencia de proyectarse como una opción política durante los primeros años de la Restauración, y creó una organización, «La

121 José Manuel Aguirre-Miramón, discurso en el Senado el 20 de julio de 1876, en Los Fueros $y$ sus defensas, Bilbao, 1897, pp. 41-42. Recogemos a Aguirre-Miramón por estar alineado, con algunas vacilaciones, con los transigentes.

122 «Al cabo de acabar yo mi primer año de bachillerato, el 21 de julio de 1876 (...) se dictó la ley abolitoria de los Fueros (...). Y en medio de la agitación de espíritus que a esa medida se siguió fue formándose mi espíritu. De aquí mi exaltación patriótica de entonces. Todavía conservo cuadernillos de aquel tiempo, en que en estilo lacrimógeno (...), lloraba la postración y decadencia de la raza, invocaba al árbol de Guernica...». UnAMUNO, Miguel de: Recuerdos de niñez y de mocedad, Bilbao, reed. 1990, p. 117. El testimonio de Gascue en Fuerismo Histórico y Fuerismo Progresivo en Guipúzcoa, San Sebastián, 1907, p. 7. Páginas brillantes sobre la adolescencia meláncolica de Unamuno, en JUARISTI, Jon: El bucle meláncolico, Madrid, 1997, pp. 65 y ss. 
Unión Vasco Navarra», de base vizcaína y sustentada en torno a F. de Sagarmínaga, y en la que figuraban asimismo conocidos intransigentes como el alavés Martínez Aragón, que no llegó a cuajar. Sus repetidos intentos electorales resultaron un fiasco ${ }^{123}$ y sólo en Vizcaya se mantuvo, pero llevando una vida lánguida ${ }^{124}$. El momento de la intransigencia había pasado, y las diversas fuerzas políticas se acomodaron al nuevo sistema tratando de extraer de él distintas ventajas.

Curiosamente, fue la línea transigente la que a medida que transcurrió la Restauración se demostró como la más viable y operativa. La política vasca de ese período transcurrió en lo que afectaba a las relaciones entre el País y el Estado dentro de unos moldes por lo general moderados y flexibles, aceptando las fuerzas vascas las reglas de juego, sin que ello impidiera que al propio tiempo se formularan distintas reivindicaciones. En que se mantuviera ese tono no disonante ayudó el establecimiento del Concierto Económico, que actuó como amortiguador de tensiones, y en este sentido no cabe duda que la apuesta de una determinada transigencia del País, así como de Cánovas, reportó indudables beneficios a las provincias vascas.

Siempre nos quedará saber qué hubiera pasado si Cánovas hubiera aguantado el empujón de la opinión pública española y hubiera sido, como le demandaba Lasala, más flexible y no hubiera tenido tanto rigor en los "principios». En cualquier caso, era una hipótesis de difícil aplicación dadas las ideas de Cánovas, y el contexto tanto nacional como internacional. Más factible es suponer lo que hubiera sucedido si la política transigente hubiera salido triunfante en esa coyuntura de 1876-1877: el espejo navarro es un buen guía para intuir por dónde podían haber discurrido las cosas (con la ventaja añadida, en el caso vascongado, de la continuidad de las antiguas instituciones forales) y cómo hubiera salido el País Vasco de esta crisis.

Sin embargo, la imagen que se transmitió desde los medios vascos, y que quedó como dominante en este territorio, fue que con la Ley de julio se había producido la abolición de los Fueros, y que el responsable de tal suceso era Cánovas en exclusiva. Además, este hecho se presentó a la sociedad vasca como una especia de hecatombe, de desastre casi apocalíptico, pues con la Ley de julio se producía «la abolición de las libertades vascongadas, de las libertades más antiguas del mundo (...) al amparo de cuyo régimen ha vivido feliz y dichoso» «el país vascongado» ${ }^{125}$. Se difundirá así un sentimiento de agravio, que fue el mejor so-

${ }^{123}$ En las elecciones de 1879 fueron elegidos Sagarmínaga en Vizcaya y P. de Egaña en Guipúzcoa, pero eran unos resultados muy distantes de los que ellos mismos esperaban. No podemos obviar que eran elecciones censitarias y además corrompidas, pero diversos indicadores confluyen en su pérdida de influencia.

124 Sobre este punto, como sobre tantos otros, CORCUERA, Javier: Orígenes, ideología y organización del nacionalismo vasco 1876-1904, Madrid, 1979, pp. 122 y ss. (el libro ha sido recientemente reeditado con el título de La Patria de los Vascos).

125 Del discurso en el Congreso, en julio de 1876, de uno de los más reputados fueristas. M. Benigno de Moraza y recogido en el libro Discursos de Mateo Benigno de Moraza en defensa de los Fueros Vascongados, julio de 1876-mayo de 1877, Vitoria, 1976, p. 8.

Hispania, LXV/2, núm. 220 (2005) 601-642 
porte para reforzar esa imagen mitificada de la edad de oro que supuestamente habían vivido las Provincias Vascongadas bajo el régimen foral. No se escatimarán adjetivos al régimen foral, que se presentará como un símbolo de prestigio, vaciado de contenidos reales, con lo que así servía mejor a su función mitológi$\mathrm{Ca}^{126}$. Se reforzaba la visión sacralizada del Fuero, que había de avivar, al estilo que nos recuerda $\mathrm{O}^{\prime}$ Brien para Irlanda, las voces ancestrales ${ }^{127}$, las emociones que tendían a exaltar la propia identidad. El diputado al Congreso por Vizcaya, Vicuña, avisaba con ocasión de la discusión de la Ley de julio en el Congreso:

«La religión de los fueros permanecerá tan pura y tan santa como hasta aquí ha vivido; y cuando la matrona vizcaína vea salir a su marido para ejercer un derecho cívico, le dirá a la manera de la matrona irlandesa de que nos habla la historia de $\mathrm{O}^{\prime}$ Conell: Acuérdate de tu bonor y de tus fueros» 128 .

Se forjó de este modo en el País Vasco una memoria de aquellos acontecimientos repleta de fustración, sin matices ni puntos positivos, y en la que sólo emergía la injusticia del poder central eliminando un régimen secular. Incluso autores posteriores con una visión más afinada, seguían interpretando aquello sucesos en clave de considerar a Cánovas cómo único culpable ${ }^{129}$, sin mencionar en ningún caso la responsabilidad que podía caber a los propios vascos. Se podría conjeturar qué hubiera ocurrido si las vías de entendimiento hubieran fructificado, pero es una hipótesis que se demostró que no era viable dada la atmósfera reinante tanto en el País Vasco como en el resto de España. Lo que quedó fue como un poso de descontento que se irá manifestando de diversas maneras durante la Restauración, dando la razón a aquellos autores que desde distintos sectores del País señalaban que la mejor garantía del entendimiento entre el Estado y las provincias vascas era el Fuero ${ }^{130}$, y que su alteración (o una alteración no suficientemente consensuada socialmente diríamos hoy nosotros) podría acarrear inconvenientes en esas relaciones ${ }^{131}$.

\footnotetext{
126 Una referencia clásica de MALINOWSKI, Bronislaw: Magia, ciencia, religión, Barcelona, 1982, p. 181

127 O’BrIEN, Conor Cruise: Voces ancestrales. Religión y nacionalismo en Irlanda, Madrid, 1999.

${ }_{128}$ C. de Villabaso, DSC, 14 de julio de 1876, pp. 3054 y ss. Sobre este personaje, URQUIJo, Mikel: Dos aproximaciones a la sociedad vasca del ochocientos, Bilbao, 2000.

${ }^{129}$ El repúblicano e industrial F. Goitia, por ejemplo, admitía por 1908 que Cánovas debía, en efecto, suprimir las exenciones militares y tributarias, pero tenía que haber dejado intactas las formas forales. La Autonomía Mundial, Barcelona, 1908, p. 305.

130 «(...) si precisamente hoy no hay más vínculo de unidad, por extraño que parezca que el principio de variedad, o sea los fueros, porque esta es la bandera del partido liberal, el cual la necesita para conservar su popularidad (...); si, por tanto, el sostenimiento de los fueros es una manera de realizar la unidad...». F. Lasala, DSC, 17 de julio de 1876, p. 3193.

131 «(...) y la (ley) de julio último, entre otros muchos inconvenientes, tiene el de que tiende a debilitar en aquel país el sentimiento monárquico y el sentimiento nacional (...). Por eso venimos a pediros que la deroguéis, porque os creemos a todos muy interesados también en que el país vasco mantenga vivo en el fondo de su alma el sentimiento de monarquismo y de españolismo...». M. Benigno de Moraza, discurso en el Congreso, 8 de mayo de 1877 y recogido en el libro Discursos de.., cit. p. 197.
} 